\title{
Volatilidade da Taxa de Câmbio Real Efetiva e Exportações Brasileiras
}

\section{Volatility of the Real Effective Exchange Rate and Brazilian Exports}

\author{
Karen Dias Corrêa* \\ Claudio Roberto Fóffano Vasconcelos** \\ Luiz Antônio Lima Júnior****
}

\begin{abstract}
Resumo: Este trabalho tem como objetivo analisar o efeito de longo prazo da volatilidade da taxa de câmbio real efetiva sobre os produtos básicos, semimanufaturados e manufaturados exportados do Brasil para os principais parceiros econômicos, sendo estes Estados Unidos, União Europeia e Mercosul. A literatura teórica é controversa com relação aos efeitos esperados da volatilidade sobre as exportações. O presente estudo avança em relação à literatura empírica reunida aqui em duas direções: na metodologia de mensuração empregada na volatilidade e na categoria de produtos utilizados. Para tanto, foi empregada a abordagem de cointegração via modelo ARDL, teste de Fronteira de Pesaran, Shin e Smith (2001). Os principais resultados são que há evidência de que a volatilidade tem um impacto negativo sobre as exportações brasileiras com destino ao Mercosul. Quanto às exportações para os Estados Unidos, os resultados são contraditórios, dado que apresentaram uma relação negativa entre a volatilidade e exportações dos produtos manufaturados e semimanufaturados e uma relação predominantemente positiva na análise desagregada em capítulos da NCM. Por fim, para a União Europeia, apenas na análise desagregada ocorreu a relação estatística de longo prazo entre volatilidade e exportações. Neste caso, a predominância das relações foi negativa.
\end{abstract}

Palavras-chave: Volatilidade cambial. Exportações. Cointegração.

Abstract: This work aims to analyze the long-term effect of the volatility of the real effective exchange rate on commodities, semi-manufactured and manufactured products exported from Brazil to the main economic partners, which are the United States, European Union and Mercosur. This study improved regarding the empirical literature in two directions: in the measurement methodology used in volatility and in the category of used products. In addition to this analysis, a disaggregated analysis of these exports was carried out through the main products exported to these countries. For this we used the approach of cointegration via ARDL model by Border test Pesaran, Shin e Smith (2001). The main results of the work are that there is evidence that volatility has a negative impact on Brazilian exports to Mercosur. For exports to the United States the results are contradictory, given that showed a negative relationship between volatility and exports for manufactured and semi-

\footnotetext{
* $\quad$ Mestre em Economia pelo Programa de Pós-Graduação em Economia (PPGE) da Universidade Federal de Juiz de Fora (UFJF). E-mail: karen_dias30@hotmail.com

** Professor da Faculdade de Economia e do PPGE da UFJF. E-mail: claudio.foffano@ufjf.edu.br

*** Professor da Faculdade de Economia da UJFJ, campus Governador Valadares. E-mail: luiz.lima@ ufje.edu.br
} 
manufactured goods and a largely positive relationship in the disaggregated analysis of NCM chapters. Finally, for the European Union only a disaggregated analysis was the long-term statistical relationship between volatility and exports. In this case, the dominance relations was negative.

Keywords: Exchange rate volatility. Exports. Cointegration.

JEL Classification: F31.

\section{Introdução}

A relação da variação cambial e o balanço de pagamento é tratada na literatura em termos da validade da condição de Marshall-Lerner (ML) e pela abordagem da Curva-J. Na condição ML, a soma do valor absoluto das elasticidades preço da demanda de exportações e importações, com respeito a câmbio, deve ser maior do que um, para que a depreciação cambial tenha efeito sobre a melhora da balança comercial. Na abordagem do efeito da Curva-J, uma depreciação cambial implicaria inicialmente uma deterioração da balança comercial com uma melhora da mesma em períodos posteriores. A explicação teórica para a existência do fenômeno Curva-J seria a existência, no curto prazo, de uma relativa rigidez em termos de quantum importado e exportado em função dos contratos de comércio estabelecidos (LEONARD; STOCKMAN, 2001). Desta forma, uma depreciação cambial poderia acarretar uma deterioração do saldo das transações correntes no curto prazo. Esta defasagem da resposta do fluxo de comércio à mudança na taxa de câmbio estabeleceria um padrão, no curto prazo, semelhante à letra J.

Como afirmam Bahmani-Oskooee, Economidou, Goswami (2006) e Bahmani-Oskooee e Goswami (2003), a existência da hipótese da Curva-J determinou uma reorientação nos estudos que se concentravam em estabelecer a ligação entre balança comercial e taxa de câmbio. Na literatura empírica encontram-se duas linhas de investigação para a hipótese da curva J. A primeira considera o fluxo de comércio de um país agregado com respeito ao resto do mundo, utilizando, assim, as variáveis taxa de câmbio efetiva, PIB doméstico e PIB externo ponderado pelo comércio com um grupo de países (LEONARD; STOCKMAN, 2001). A segunda linha de investigação empírica se caracteriza pela análise bilateral para o fluxo de comércio, pelo emprego das variáveis taxa câmbio real bilateral, PIB doméstico e PIB do parceiro comercial (BAHMANI-OSKOOEE; ECONOMIDOU; GOSWAMI, 2006; BAHMANI-OSKOOEE; GOSWANI, 2003; ARORA; BAHMANI-OSKOOEE; GOSWMI., 2003). Um ponto em comum entre as duas vertentes de análise citadas é que não existe um consenso acerca da efetividade da desvalorização cambial ${ }^{1}$ como instrumento para melhorar a balança comercial.

1 A definição empregada para taxa de câmbio é: número de moeda nacional em relação a uma unidade de moeda estrangeira. Logo, uma desvalorização cambial aumentaria o poder de compra da moeda estrangeira no país local e valendo a condição de Marshall-Lerner ter-se-ia um 
Neste sentido, tanto a evolução da taxa de câmbio nos anos recentes, com características de forte valorização do Real, quanto a volatilidade da taxa de câmbio, ${ }^{2}$ têm suscitado questionamentos acerca do papel da trajetória do câmbio e sua volatilidade sobre o volume de comércio internacional.

Com relação ao efeito da volatilidade de câmbio sobre o volume de comércio internacional, Bahmani-Oskooee e Hegerty (2007) salientam que os trabalhos originais partem do entendimento da existência da relação entre taxa de câmbio e volume de comércio, dadas a volatilidade e a ausência de mecanismos de risco. Um trabalho pioneiro, segundo os autores, seria o de Ethier (1973³ apud BAHMANI-OSKOOEE; HEGERTY, 2007). Ethier (1973) mostra que as dúvidas sobre a variação do valor futuro da taxa de câmbio (volatilidade cambial) fariam com que os exportadores tivessem dúvida sobre a renda futura de suas atividades, suas exportações e, consequentemente, esta maior volatilidade afetaria negativamente o volume de comércio.

O trabalho desenvolvido por Clark (1973) foi um dos primeiros a investigar esta relação entre o comércio e a volatilidade da taxa de câmbio em um ambiente no qual as firmas são avessas aos riscos. O autor propõe que aumentos na volatilidade da taxa de câmbio ocasionariam aumentos na incerteza dos lucros de exportação, os quais são expressos em moeda doméstica. Isto significa que, ao considerar firmas avessas ao risco, elas tenderiam a reduzir a oferta de bens até o ponto em que a receita marginal excedesse o custo marginal, no montante que compensaria o risco adicional. Ou seja, a volatilidade poderia deixar de ser um problema na medida em que os exportadores ou importadores pudessem repassar os riscos da variação cambial para o mercado futuro de divisas. Portanto, não existiria a relação inversa entre volatilidade cambial e fluxo de comércio. Para chegar a estas conclusões, o autor impõe algumas hipóteses restritivas, como, por exemplo, uma estrutura de mercado operando em concorrência perfeita, produção de bens pelas firmas somente para a exportação, limitadas possibilidades das firmas para hedging, em que os contratos firmados estão em moedas estrangeira, e inexistência de insumos importados.

Por outro lado, a crítica à posição de Clark seria a de que o mercado futuro de câmbio não estaria disponível para todos os países ou dependeria do desenvolvimento do mercado financeiro dos países. Além disto, os custos dos contratos futuros de câmbio podem tornar inviáveis as operações comerciais de pequeno porte.

aumento das exportações líquidas.

2 Entende-se como volatilidade a variação da taxa de câmbio, ou seja, os movimentos de aumento (desvalorização) ou redução (apreciação) da taxa de câmbio. Assim, o aumento da volatilidade implicaria uma percepção de aumento de risco nas transações comerciais.

3 ETHIER, W. International trade and the forward exchange market. American Economic Review, v. 63, n. 3, p. 494-503, 1973. 
Hooper e Kohlhagen (1978) mostram que uma elevação na volatilidade da taxa de câmbio teria um alto custo para as firmas que são avessas ao risco, por isso, tenderia a se ter um efeito negativo sobre o comércio internacional. Para os autores, o efeito negativo da volatilidade da taxa de câmbio sobre o comércio ocorreria devido ao fato da taxa de câmbio ser acordada no momento em que o contrato é assinado, entretanto, o pagamento seria realizado apenas quando a entrega do produto efetivamente ocorresse. Com isto, eles notaram que, caso a mudança na taxa de câmbio se torne imprevisível, isto criaria uma incerteza acerca da receita de exportação e, por conseguinte, reduziria os benefícios do comércio internacional. Os autores apontam ainda que a proteção diante da volatilidade da taxa de câmbio muitas vezes não é perfeitamente realizada, porque as opções de hedge ou não estão disponíveis para todas as firmas ou, quando estão, possuem custos elevados. Assim, a volatilidade da taxa de câmbio terá um efeito negativo sobre o montante de risco que não foi protegido pelo mercado futuro.

Outros trabalhos teóricos (como LIN, 2012), no entanto, mostram que o aumento da volatilidade da taxa de câmbio pode ter o efeito contrário, incrementando volume de comércio. Viaene e De Vries (1992) observaram que, porque os importadores e exportadores estão em lados opostos de uma relação comercial arriscada, seus respectivos papéis são invertidos, levando a um coeficiente positivo sobre a variável volatilidade e fluxo de comércio. Franke (1991) demonstra que, em condições muito gerais, uma empresa pode se beneficiar de uma maior volatilidade e, assim, aumentar o volume de suas exportações em resposta.

Porém, há outros trabalhos que mostram que a volatilidade não tem impacto perceptível sobre o volume do comércio internacional (WILLETT, 1986). O autor observou que não havia evidência empírica, à época, para a relação de aumento de volatilidade e redução esperada do comércio. Willett mostrou ainda que o nível de agregação da análise pode alterar os resultados esperados, tal que para a análise muito agregada se observa uma maior ocorrência de efeito negativo da volatilidade, enquanto em nível mais desagregado, de indústria específica, há a ocorrência de efeito positivo. Portanto, o nível de agregação da análise contribui para o grande corpo de literatura teórica que prediz que a volatilidade vai ter um efeito negativo, um efeito positivo, ou nenhum efeito sobre os fluxos comerciais.

Neste contexto, o objetivo do presente trabalho é o de verificar qual o efeito, principalmente o de longo prazo, da volatilidade da taxa de câmbio sobre as exportações brasileiras dos produtos básicos, semimanufaturados e manufaturados, considerando para isto os principais parceiros comerciais brasileiros, como Estados Unidos, União Europeia e Mercosul. Além deste fato, busca-se também analisar o efeito da volatilidade cambial nas exportações de forma desagregada para estes países, considerando para isto o período de Janeiro de 2000 a Outubro de 
2014. Para tanto, utilizou-se o método cointegração via modelos autorregressivo de defasagem distribuída - ARDL de Pesaran, Shin e Smith (2001).

Além desta seção, na seção 2 procura-se explicar a relação entre volatilidade e balança comercial para a economia brasileira. A terceira seção apresenta a metodologia, bem como o modelo empírico a ser testado. A quarta apresenta os resultados, e por fim, na seção 5, estão as considerações finais.

\section{Relação da Taxa de Câmbio com a Balança Comercial Brasileira}

Alguns autores procuraram entender melhor a relação entre a volatilidade cambial e as exportações para a economia brasileira. Entre eles, pode-se observar o trabalho de Aguirre, Ferreira e Notini (2007), em que estes autores procuraram analisar o efeito da volatilidade da taxa de câmbio sobre as exportações brasileiras de manufaturados. Para isto, os autores utilizaram como variáveis, além de uma medida da volatilidade da taxa real de câmbio, a taxa de câmbio real efetiva, o nível de importação mundial, e a taxa da capacidade utilizada da indústria nacional. Para estimar o modelo foi utilizado o método ARDL (Auto-Regressive Distributed Lag) de cointegração de Pesaran, Shin e Smith (2001), sendo o período analisado o de 1986 a 2002. Neste trabalho, os autores concluíram que o coeficiente associado à volatilidade da taxa real de câmbio seria negativo e estatisticamente significativo, e que o aumento de $1 \%$ na volatilidade da taxa real de câmbio causaria uma redução de $0,77 \%$ nas exportações brasileiras de manufaturados.

O trabalho desenvolvido por Bahmani-Oskooee, Harvey e Hegerty (2013) analisou os fluxos de exportação e importação bilaterais entre os Estados Unidos e o Brasil durante o período de 1971 a 2010, usando para isto uma análise de cointegração via modelos ARDL de cointegração de Pesaran, Shin e Smith (2001) de forma a estimar os efeitos deste risco. Neste estudo uma das conclusões foi que a maioria das indústrias não seria afetada pela volatilidade cambial a longo prazo, entretanto, algumas das indústrias que seriam afetadas tenderiam a responder de forma positiva para o aumento do risco. Outra conclusão seria com relação à sensibilidade ao risco, em que esta diferiria em cada setor da indústria, ou seja, as exportações brasileiras de produtos agrícolas seriam particularmente prejudicadas de acordo com os autores, enquanto as importações dos Estados Unidos de máquinas não seriam afetadas em tudo. Por fim, os autores concluíram que os produtos com pequenas quotas de comércio tenderiam a ser mais propensos a responder a um aumento da incerteza do que os que são grandes exportadores.

Bittencourt, Larson e Thompson (2007) analisaram os efeitos da volatilidade da taxa real de câmbio sobre o comércio setorial no Mercosul, para o período de 1989 a 2002. Eles estimaram equações gravitacionais de comércio, cuja variável dependente era o volume comercial bilateral dos cinco setores (Agríco- 
la, Pecuário, Químico, Manufaturados e Mineração). Já as variáveis explicativas foram: duas medidas de volatilidade da taxa real de câmbio bilateral, as tarifas aduaneiras, o PIB dos países, a distância geográfica e uma medida para o efeito "Third Country", que representava o efeito da volatilidade cambial de um terceiro parceiro comercial ao comércio bilateral considerado. Dentre os resultados apresentados, os autores observaram que, dos cinco setores analisados, quatro deles (Agrícola, Químico, Minerais e Manufaturados) eram afetados negativamente pela volatilidade da taxa de câmbio.

No trabalho desenvolvido por Carmo e Bittencourt (2013) também se analisou a relação volatilidade e comércio através de um modelo gravitacional, em que a formulação básica deste modelo seria a de que os fluxos comerciais entre os países $i$ e j são diretamente proporcionais ao tamanho econômico dos países e inversamente proporcionais à distância geográfica entre eles. Neste trabalho, os autores usaram a técnica econométrica Poisson Pseudo Maximum Likelihood (PPML). Sendo assim, acredita-se que a diversificação da pauta de exportação brasileira depende do nível da atividade econômica dos países. Então, os resultados obtidos indicaram que a volatilidade da taxa real de câmbio possui um efeito negativo, e estatisticamente significativo, sobre a diversificação da pauta de exportação brasileira.

Alguns estudos mostram a relação da volatilidade com as exportações para países selecionados. Um exemplo é o estudo de Bahmani-Oskooee e Mitra (2008), que analisaram o impacto que a incerteza cambial tem sobre o comércio que flui entre os Estados Unidos e a economia emergente da Índia. Neste estudo, os autores desagregaram os dados do comércio entre os dois países por commodities. Com isto, a metodologia se baseou na abordagem do teste de fronteira de cointegração de Pesaran, Shin e Smith (2001). Os autores analisaram 40 indústrias durante o período de 1962 a 2004, em que puderam concluir que a incerteza da taxa de câmbio tem mais efeitos no curto prazo do que efeitos de longo prazo. Além disso, observaram que, no curto prazo, 17 indústrias foram afetadas negativamente pela volatilidade pelo lado das importações e no lado das exportações 15 indústrias foram afetadas pela volatilidade. No entanto, na análise de longo prazo, o coeficiente de volatilidade foi estatisticamente significativo apenas para o fluxo de comércio de algumas indústrias.

O estudo de Verheyen (2012) investiga a relação da volatilidade câmbio para as exportações considerando 11 países da União Monetária Europeia (UEM). Para esta análise, o autor adota a abordagem de cointegração via ARDL para analisar a volatilidade da taxa de câmbio. Os resultados encontrados pelo autor sugerem que a volatilidade exerce uma significante influência nas exportações da UEM e que o sinal é tipicamente negativo, sendo que tal resultado foi mais frequente para os produtos da categoria 6 da classificação padrão de comércio internacional - SITC. 
Segundo Verheyen (2012), os resultados são em geral coerentes com a evidência escassa sobre a relação entre a variabilidade da taxa de câmbio e o comportamento das exportações. Além disso, os resultados empíricos obtidos no estudo de Verheyen (2012) são consistentes com estudos recentes que mostram um significativo (longo prazo) impacto negativo da volatilidade da taxa de câmbio sobre os fluxos de exportação para os países em desenvolvimento da America Latina (ver, por exemplo, ARIZE; OSANG; SLOTTJE, 2008).

De forma sintética, observa-se no Quadro 1 que há uma maior incidência do emprego da abordagem de cointegração via modelo ARDL, baseado em Pesaran, Shin e Smith (2001), e que também há uma maior ocorrência de efeitos negativos sobre as exportações e importações. Duas questões importantes tratadas na literatura para explicar os resultados divergentes, como visto no Quadro 1, são o nível de agregação da análise e a análise par a par da relação comercial. Neste sentido, o presente trabalho procura tratar estas duas questões.

Quadro 1 - Resumo da análise da volatilidade cambial sobre o fluxo de comércio

\begin{tabular}{|l|l|l|l|}
\hline \multicolumn{1}{|c|}{ Autor } & \multicolumn{1}{|c|}{ Objetivo } & Metodologia & \multicolumn{1}{c|}{ Conclusão } \\
\hline $\begin{array}{l}\text { Aguirre, Ferreira e } \\
\text { Notini (2007). }\end{array}$ & $\begin{array}{l}\text { Analisar o efeito } \\
\text { da volatilidade so- } \\
\text { bre as exportações } \\
\text { brasileiras de ma- } \\
\text { nufaturados, 1986 } \\
\text { a 2002. }\end{array}$ & $\begin{array}{l}\text { Cointegração via } \\
\text { modelo ARDL. }\end{array}$ & $\begin{array}{l}\text { Efeito negativo da volati- } \\
\text { lidade sobre as exporta- } \\
\text { ções. }\end{array}$ \\
\hline $\begin{array}{l}\text { Bahmani-Oskooee, } \\
\text { Harvey e Hegerty } \\
\text { (2013). }\end{array}$ & $\begin{array}{l}\text { Estuda as exporta- } \\
\text { çes e importações } \\
\text { brasileiras com os } \\
\text { EUA, 1971 a 2010. }\end{array}$ & $\begin{array}{l}\text { Cointegração via } \\
\text { modelo ARDL. }\end{array}$ & $\begin{array}{l}\text { A maioria das indústrias } \\
\text { investigadas não foram } \\
\text { afetadas pela volatilidade. } \\
\text { Nas que apresentaram al- } \\
\text { gum impacto, o efeito foi } \\
\text { positivo. }\end{array}$ \\
\hline $\begin{array}{l}\text { Bittencourt, Lar- } \\
\text { son e Thompson } \\
(2007) .\end{array}$ & $\begin{array}{l}\text { Analisam o comér- } \\
\text { cio brasileiro com } \\
\text { relação ao Merco- } \\
\text { sul para o período } \\
\text { entre 1989 e 2002. }\end{array}$ & $\begin{array}{l}\text { Equação gravita- } \\
\text { cional. }\end{array}$ & $\begin{array}{l}\text { Os setores agrícola, quí- } \\
\text { mico, minerais e manu- } \\
\text { faturados seriam afeta- } \\
\text { dos negativamente pela } \\
\text { maior volatilidade. }\end{array}$ \\
\hline $\begin{array}{l}\text { Carmo e Bitten- } \\
\text { court (2013). }\end{array}$ & $\begin{array}{l}\text { Análise do efeito } \\
\text { da volatilidade so- } \\
\text { bre a diversificação } \\
\text { da pauta de expor- } \\
\text { tações brasileira. }\end{array}$ & $\begin{array}{l}\text { Equação gravita- } \\
\text { cional. }\end{array}$ & $\begin{array}{l}\text { Evidenciou um efeito ne- } \\
\text { gativo sobre a pauta de } \\
\text { exportações. }\end{array}$ \\
\hline
\end{tabular}

continua... 


\begin{tabular}{|l|l|l|l|}
\hline \multicolumn{1}{|c|}{ Autor } & \multicolumn{1}{|c|}{ Objetivo } & \multicolumn{1}{c|}{ Metodologia } & \multicolumn{1}{c|}{ Conclusão } \\
\hline $\begin{array}{l}\text { Arize, Osang; Slot- } \\
\text { tje (2008). }\end{array}$ & $\begin{array}{l}\text { Verificar o efeito da } \\
\text { volatilidade sobre } \\
\text { as exportações de } \\
\text { oito países da Amé- } \\
\text { rica Latina, 1973 a } \\
\text { 2004. }\end{array}$ & $\begin{array}{l}\text { Modelos de coin- } \\
\text { tegração (Harris- } \\
\text { Inder; Johansen; } \\
\text { Shin; Gregory- } \\
\text {-Hansen e Han- } \\
\text { sen). }\end{array}$ & $\begin{array}{l}\text { O aumento da volatilida- } \\
\text { de apresentaria efeito ne- } \\
\text { gativo nas exportações no } \\
\text { curto e longo prazo. }\end{array}$ \\
\hline $\begin{array}{l}\text { Bahmani-Oskooee } \\
\text { e Mitra (2008). }\end{array}$ & $\begin{array}{l}\text { Investigam o co- } \\
\text { ércio entre EUA } \\
\text { indústrias, para 40 1962 a } \\
\text { 2004. }\end{array}$ & $\begin{array}{l}\text { Cointegração via } \\
\text { modelo ARDL. }\end{array}$ & $\begin{array}{l}\text { Evidenciou efeito negati- } \\
\text { vo do aumento da vola- } \\
\text { tilidade para 15 indústrias } \\
\text { nas exportações e 17 para } \\
\text { as importações. }\end{array}$ \\
\hline Verheyen (2012). & $\begin{array}{l}\text { Investiga as expor- } \\
\text { tações de onze paí- } \\
\text { ses da UEM. }\end{array}$ & $\begin{array}{l}\text { Cointegração via } \\
\text { modelo ARDL. }\end{array}$ & $\begin{array}{l}\text { Encontra evidência de } \\
\text { efeito negativo da volati- } \\
\text { lidade sobre as exporta- } \\
\text { ções. }\end{array}$ \\
\hline
\end{tabular}

Fonte: Elaboração própria.

\section{Metodologia}

Para analisar a influência da volatilidade da taxa de câmbio sobre as exportações brasileiras com relação aos seus grandes parceiros comerciais, levando em conta os produtos agregados e desagregados exportados pelo país, utilizou-se o modelo de cointegração baseado no teste de fronteira de Pesaran, Shin e Smith (2001) que requer que as variáveis dos modelos sejam de ordem de integração menor que dois.

Sendo assim, calculou-se, primeiramente, a volatilidade da taxa de câmbio com base no desvio padrão móvel da taxa de câmbio real efetiva para um intervalo de três, seis e doze meses. Dada a determinação do modelo baseado em uma função de exportações, realizou-se teste de raiz unitária para verificar a estacionariedade das séries, sendo neste caso empregados os testes de GLS-detrending (ELLIOTT; ROTHENBERG; STOCK, 1996, de agora em diante chamado de DF-GLS) ${ }^{4}$ e o teste de NG-Perron (NG; PERRON, 2001). ${ }^{5}$ Empregou-se também o

4 Como é conhecido na literatura, o teste de $\mathrm{ADF}$ apresentaria sérias distorções de tamanho e poder. Assim, o teste $\mathrm{ADF}$ teria baixo poder, ou seja, baixa probabilidade de rejeitar a hipótese nula quando ela realmente é falsa e a questão do problema do tamanho do teste estaria relacionado à probabilidade de erroneamente rejeitar a hipótese nula. Neste contexto, Elliot, Rothemberg e Stock (1996) e Ng e Perron (2001) desenvolvem novos procedimentos de teste de raiz unitária de forma a atacar os problemas de poder e tamanho do teste ADF para séries de tempo que apresentem alta persistência. Elliot, Rothemberg e Stock (1996) propõem um teste eficiente modificando o teste de Dickey-Fuller usando ao invés do método de mínimos quadrados ordinários, $\mathrm{MQO}$, a estrutura de mínimos quadrados generalizados, GLS. Eles demonstram que este modificado tem melhor desempenho global em termos de tamanho e poder para séries com pequena amostra.

5 O teste de Ng e Perron (2001) de raiz unitária também procura melhorar o poder do teste para as 
teste de raiz unitária com quebra estrutural baseado em Lee e Strazicich (2003 e 2013) que permite tornar endógeno o período das quebras. O teste de Lee e Starzicich tem a característica de incluir a quebra estrutural tanto na hipótese nula quanto na alternativa. Desta forma, quando há rejeição da hipótese nula tem-se que a série é realmente estacionária com quebra estrutural. ${ }^{6}$

Após a análise destes testes, pode-se realizar o teste de fronteira de Pesaran, Shin e Smith (2001), que é baseado em uma estrutura ARDL. O objetivo deste teste é mostrar as análises de longo prazo provocadas pela volatilidade do câmbio sobre as exportações brasileiras.

Inicialmente a análise dos produtos exportados se deu em um nível de agregação definido por fator agregado, ou seja, produtos básicos, semimanufaturados e manufaturados. Após esta análise, com o intuito de observar se está ocorrendo o chamado viés de agregação, isto é, se os resultados são sensíveis ao nível de agregação dos dados, procedeu-se à análise dos dados desagregados a seis dígitos do sistema de nomenclatura comum do Mercosul - NCM.

Para a definição desta amostra considerou-se a participação das exportações brasileiras com relação aos Estados Unidos (EUA), Mercosul (MER) e União Europeia (EU). Sendo assim, observou-se que para o ano de 2013, os produtos básicos exportados para EU correspondiam a 52\% do total exportado pelo Brasil, e os produtos manufaturados exportados para EUA e Mercosul correspondiam a $54 \%$ e $72 \%$ do total exportado, respectivamente (BRASIL, 2015). Assim sendo, selecionou-se para a análise desagregada as exportações de produtos básicos para a União Europeia e os produtos manufaturados para os Estados Unidos e Mercosul. Portanto, levantou-se informações de exportações desagregadas a seis dígitos da NCM, classificou-se estes produtos de acordo com a definição de fator agregado e agruparam-se estas informações para análise em capítulos da NCM.

séries com presença de média móveis altas. O teste de Ng e Perron (2001) busca resolver ou minimizar o problema do tamanho de lags selecionados do teste quando se observa a presença de raiz unitária, já que os critérios de informação (AIC e BIC) tendem a escolher pequenos números de lags. Além disto, o teste de Ng e Perron não sofre do problema de tamanho de amostra quando a raiz unitária do erro do processo estiver próxima de um. Então, baseado na ideia da escolha da densidade espectral autorregresiva do estimador, Ng e Perron (2001) propuseram modificações nos critérios de informação para a escolha da defasagem ótima, levando em conta os testes são sensiveis ao tamanho da defasagem autorregressiva.

6 O modelo desenvolvido por Lee e Strazicich (2003 e 2013) foi baseado no modelo de quebras estruturais proposto inicialmente por Perron (1989), porém diferente deste último, os autores procuraram realizar um teste em que se permite analisar as quebras estruturais com duas mudanças do nível da série. Sendo assim, neste teste têm-se dois modelos, o modelo A denominado de "crash", em que se pode analisar uma ou duas quebras estruturais no nível e na tendência da série, e o modelo C que é denominado de "break", em que se analisam quebras estruturais no nível da série. Com isto, pode-se perceber que o teste proposto por Lee e Strazicich (2003) para raiz unitária com duas quebras estruturais equivale ao teste de raiz unitária via o mínimo multiplicador de Lagrange, porém, este considera que a quebra estrutural seria determinada endogenamente. 


\subsection{Volatilidade da Taxa de Câmbio}

Para estimar volatilidade cambial, tomou-se como base o artigo de Bahmani-Oskooee e Hegerty (2007) que apresenta várias abordagens de volatilidade cambial. Segundo estes autores, não existe na literatura um consenso sobre qual abordagem ou mensuração de volatilidade deve ser preferida. Entretanto, observa-se um predomínio nos trabalhos empíricos da escolha pela abordagem do cálculo do desvio padrão e desvio padrão móvel e dos processos estocástico autorregressivo dos erros heterocedástico e generalizado, ARCH e GARCH. Esta última abordagem de cálculo da volatilidade se adequa melhor à análise de dados de alta frequência, o que não é o caso do presente estudo.

A definição de taxa de câmbio real efetiva utilizada, TCRE, foi a de número de moeda nacional em termos de unidade de moeda estrangeira deflacionadas pelos respectivos níveis de preços internos e ponderadas pelos pesos dos fluxos comerciais do país seus principais parceiros.

Após se definir a série da TCRE, realizou-se a logaritimização natural desta série para que se obtivesse um modelo mais consistente. O modelo de volatilidade foi estimado através do cálculo do desvio padrão da TCRE para os períodos de três, seis e doze meses, ou seja,

$$
V O L=\sqrt{\frac{1}{n-1} \sum_{i=1}^{n}\left(T C R E_{i}-\overline{T C R E}\right)^{2}}
$$

onde VOL é a volatilidade, $n$ é o número de informações utilizadas; $\overline{T C R E}$ é a taxa de câmbio real efetiva média para os períodos de três, seis e doze meses.

\subsection{Cointegração via Modelos ARDL}

Para o processo de cointegração, utilizou-se a abordagem do teste de fronteira proposta pelos autores Pesaran, Shin e Smith (2001). Este teste de cointegração se baseia em modelos autorregressivos de defasagens distribuídas (ARDL). A abordagem de Pesaran, Shin e Smith (2001) propõe-se a testar se há uma relação de longo prazo entre as variáveis, sem que para isto se analise a ordem de integração destas. Entretanto, o teste é especificado para variáveis com ordem de integração menor do que dois. Para esta análise, o teste é estimado utilizando como base a dinâmica do modelo de correção de erros, além de ser possível testar se as variáveis defasadas conjuntas são diferentes de zero.

Segundo Pesaran, Shin e Smith (2001), partindo de um vetor autorregressivo de ordem $\mathrm{p}(\mathrm{VAR}(\mathrm{p}))$, pode-se especificar o seguinte modelo de correção de erros (ECM): 


$$
\Delta x_{t}=a_{0}+b_{1} x_{t-1}+b_{2} y_{t-1}+\sum_{i=1}^{p-1} \gamma \Delta x_{t-i}+\sum_{i=0}^{p} \phi \Delta y_{t-i}+\mu_{t}
$$

onde $\mu_{\mathrm{t}}$ é um processo white noise, $\mathrm{N}\left(0, \sigma^{2}\right)$, identicamente, independentemente distribuída, iid.

Uma das características desta abordagem de cointegração, Teste de Fronteira de Pesaran, Shin e Smith (2001), é que ela não requer a pressuposição restritiva de que todas as variáveis sob estudo devam ser integradas de mesma ordem para testar a existência de uma relação de longo prazo entre duas ou mais variáveis.

Confirma-se o equilíbrio de longo prazo simétrico entre as variáveis se $b_{1}$ e $b_{2}$, conjuntamente, são diferentes de zero. Segundo Pesaran, Shin e Smith (2001), o teste é para a falta de alguma relação de longo prazo entre as variáveis. A hipótese nula do teste contempla, portanto, a possibilidade de que não exista uma relação de longo prazo entre a variável dependente e as variáveis independentes, a despeito da ordem de integração das variáveis.

Assim, segundo os autores, o teste envolve dois conjuntos assintóticos, fronteira, de valores críticos. Então, se o valor calculado da estatística $\mathrm{F}$ (de agora em diante denominado $\mathrm{F}_{\mathrm{PSS}}$ ) for menor ou maior do que os valores críticos inferiores e superiores (fronteira), ${ }^{7}$ respectivamente, uma inferência conclusiva pode ser tirada sem a necessidade de se conhecer a ordem de integração das variáveis envolvidas. Isto é, se o valor do teste de hipótese conjunta (teste $\mathrm{F}_{\mathrm{PSS}}$ ) calculado for menor que o valor crítico para I(0), pode-se inferir que não existe uma relação de longo prazo entre as variáveis, independentemente dos regressores serem I(0) ou I(1). Caso contrário, se o $\mathrm{F}_{\mathrm{PSS}}$ calculado for maior que o valor crítico para I(1), a hipótese de que não existe relação de longo prazo é rejeitada. Por fim, se o valor calculado de $\mathrm{F}$ for maior que o valor crítico para I(0) e menor que o valor crítico I(1), a inferência pode ser inconclusiva. Neste caso, será necessário conhecer a ordem de integração das variáveis envolvidas antes de se fazer alguma afirmação.

\subsection{Estratégia Empírica e Banco de Dados}

Para testar o efeito da volatilidade da taxa de câmbio sobre a balança comercial brasileira tendo como base os maiores parceiros comerciais, utilizou-se o modelo proposto na abordagem de Bahmani-Oskooee e Harvey (2013):

$7 \quad$ Pesaran et al. (2001, p. 300) proveem as tabelas de valores críticos com dois conjuntos de valores críticos assintóticos para a estatística F cobrindo cinco especificações da equação (2). Um conjunto assume que a variável explicativa (ou conjunto de variáveis explicativas) é I(0) e outro assume que seja I(1). 


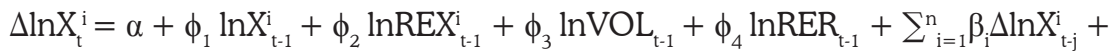

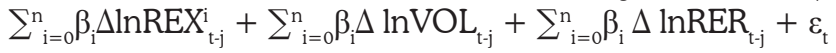

onde $\operatorname{lnVOL} \mathrm{L}_{\mathrm{t}-1}$ representa o logaritmo da volatilidade da taxa de câmbio real efetiva brasileira e $\ln X_{t}^{i}$ representa o logaritmo dos valores das exportações entre Brasil e EUA, União Europeia e Mercosul. lnREX $\mathrm{X}_{\mathrm{t}-1}$ representa o logaritmo da renda externa dos países analisados e $\operatorname{lnRER} R_{t-1}$ representa a taxa de câmbio real efetiva brasileira.

Para realizar a análise da influência da volatilidade cambial sobre a balança comercial, obtiveram-se dados sobre as exportações brasileiras de produtos básicos, semimanufaturados e manufaturados para seus principais parceiros comerciais, sendo estes Estados Unidos (EUA), União Europeia (EU) e Mercosul (MER), já que esses parceiros comerciais corresponderam a, aproximadamente, $62 \%$ do total das exportações realizadas pelo Brasil no ano de 2013 (BRASIL, 2015). Os dados são de periodicidade mensal, sendo que englobam o período correspondente entre janeiro de 2000 a outubro de 2014. Esses dados foram obtidos através do sistema AliceWeb2s do Ministério de Desenvolvimento, Indústria e Comércio Exterior (MDIC).

Com relação à variável taxa de câmbio, empregou-se a taxa de câmbio real efetiva - TCRE do Bank for International Settlements (BIS) com periodicidade mensal e base $2010=100$. As TCRE do BIS são calculadas como médias geométricas ponderadas das taxas de câmbio bilaterais ajustadas pelo índice de preços no consumidor relativos. O padrão de ponderação é variável no tempo e os pesos mais recentes são baseados sobre o fluxo comércio de 2008 (BANK FOR INTERNATIONAL SETTLEMENTS, 2014).

Para a variável nível de renda externa, como a periodicidade é mensal foi empregado o índice de produção industrial dos Estados Unidos, da União Europeia e da Argentina como proxy para a renda do Mercosul, obtidos pelo banco de dados do Fundo Monetário Internacional - FMI. Todas as variáveis de exportações tiveram seus valores denominados em Dólares deflacionados pelo índice de preços ao consumidor dos Estados Unidos e foram dessasonalizadas pelo método X12.

\section{Resultados}

Inicialmente procedeu-se à verificação da ordem de integração das variáveis com o intuito de se observar se são integradas de ordem menor que dois, I(2). Para tanto foram executados os testes de raiz unitária de DF-GLS e Ng-Perron para as variáveis em nível e na primeira diferença. Entretanto, a presença de quebras estruturais nas séries compromete os resultados dos testes de raiz unitária tradicionais no sentido de aumentar rejeição da hipótese de estacionariedade quando a série é estacionária com presença de quebras. Assim, realizou-se também, para os 
casos de resultados de não estacionariedade na primeira diferença, o teste para raiz unitária com quebras estruturais determinadas endogenamente de Lee e Strazicich $(2003,2013)$.

As Tabelas 1, 2 e 3, XB, XS e XM representam as exportações de produtos básicos, semimanufaturados e manufaturados, respectivamente, e o subscrito EUA, EU e MER referem-se ao destino das exportações, Estados Unidos, União Europeia e Mercosul. PI diz respeito à Produção Industrial, TCRE é a taxa de câmbio real efetiva e VOL é a volatilidade da taxa de câmbio para 3, 6 e 12 períodos.

Desta forma, a Tabela 1 apresenta os resultados para os testes de raiz unitária para as variáveis em nível. Neste caso, somente as exportações de produtos semimanufaturas para os EUA e Mercosul e as volatilidades foram estacionárias em nível pelos dois critérios utilizados. Com relação à volatilidade este resultado já era esperado dada a característica de sua confecção.

Tabela 1 - Teste de raiz unitária, DF-GLS e Ng-Perron, variáveis em nível

\begin{tabular}{c|ccccc}
\hline Variável & DF-GLS & MZA & MZT & MSB & MPT \\
\hline $\mathrm{XB}_{\mathrm{EUA}}$ & $-1,779$ & $-5,168$ & $-1,554$ & 0,300 & 17,422 \\
$\mathrm{XB}_{\mathrm{EU}}$ & $-1,977$ & $-7,609$ & $-1,871$ & 0,245 & 12,170 \\
$\mathrm{XB}_{\mathrm{Mer}}$ & $-1,094$ & $-3,288$ & $-1,089$ & 0,331 & 24,010 \\
$\mathrm{XS}_{\mathrm{EUA}}$ & $-2,640 * *$ & $-12,35 * *$ & $-2,485 * *$ & 0,201 & 1,9830 \\
$\mathrm{XS}_{\mathrm{EU}}$ & $-2,139$ & $-7,899$ & $-1,890$ & 0,239 & 11,809 \\
$\mathrm{XS}_{\mathrm{Mer}}$ & $-3,588 * *$ & $-21,90 * *$ & $-3,296 * *$ & 0,150 & 4,2381 \\
$\mathrm{XM}_{\mathrm{EUA}}$ & $-1,263$ & $-3,151$ & $-1,255$ & 0,398 & 28,915 \\
$\mathrm{XM}_{\mathrm{EU}}$ & $-1,651$ & $-5,243$ & $-1,404$ & 0,267 & 16,647 \\
$\mathrm{XM}_{\mathrm{Mer}}$ & $-1,468$ & $-6,342$ & $-1,729$ & 0,272 & 14,371 \\
$\mathrm{PI}_{\mathrm{EUA}}$ & $-0,882$ & $-2,768$ & $-0,930$ & 0,336 & 25,991 \\
$\mathrm{PI}_{\mathrm{EU}}$ & $-2,631$ & $-16,51 * * *$ & $-2,873 *$ & 0,174 & 5,5194 \\
$\mathrm{PI}_{\mathrm{Mer}}$ & $-1,775$ & $-6,374$ & $-1,775$ & 0,278 & 14,296 \\
$\mathrm{TCRE}$ & $-2,114$ & $-9,139$ & $-2,120$ & 0,232 & 10,041 \\
VOL3 & $-3,109 * *$ & $-16,09 * * *$ & $-2,825 * *$ & 0,175 & 5,7332 \\
$\mathrm{VOL6}$ & $-2,641 * *$ & $-12,74 * *$ & $-2,501 * *$ & 0,196 & 2,0153 \\
$\mathrm{VOL}_{12}$ & $-2,823 *$ & $-181,2 * * *$ & $-9,515 * *$ & 0,052 & 0,5160 \\
\hline
\end{tabular}

Fonte: Elaboração própria.

Nota: *, **, *** denotam nível de significância a 10\%, 5\% e 1\%, respectivamente. Teste realizado para intercepto e tendência e utilizando o critério AIC modificado para a seleção das defasagens.

Com relação aos testes de raiz unitária em primeira diferença para aquelas variáveis que não foram I(0), a Tabela 2 aponta que as exportações de básicos para 
os EUA e EU, exportações de semimanufaturado para o Mercosul, a Produção Industrial da União Europeia, Mercosul e Estados Unidos e a taxa de câmbio real efetiva, TCRE, são estacionários na primeira diferença. Neste caso, para as demais variáveis que não foram estacionárias na primeira diferença realizou-se o teste de raiz unitária com quebra estrutural para as variáveis em nível, pois, dadas as características das séries, a possibilidade de existência de quebra estrutural pode estar influenciando os testes de raiz unitária padrão.

Tabela 2 - Teste de raiz unitária, DF-GLS e Ng-Perron, variáveis em primeira diferença

\begin{tabular}{|c|c|c|c|c|c|}
\hline Variável & DF-GLS & MZA & MZT & MSB & MPT \\
\hline $\mathrm{XB}_{\mathrm{EUA}}$ & $-18,336 * * *$ & $-79,242^{* * *}$ & $-6,294 * * *$ & 0,079 & 1,152 \\
\hline $\mathrm{XB}_{\mathrm{EU}}$ & $-21,783 * * *$ & $-69,286^{* * *}$ & $-5,885 * * *$ & 0,084 & 1,315 \\
\hline $\mathrm{XB}_{\text {Mer }}$ & $-1,631$ & $-0,076$ & $-0,090$ & 1,185 & 267,5 \\
\hline $\mathrm{XS}_{\mathrm{EU}}$ & $-1,842$ & $-0,499$ & $-0,448$ & 0,896 & 149,4 \\
\hline $\mathrm{XM}_{\mathrm{EUA}}$ & $-1,413$ & $-0,136$ & $-0,178$ & 1,313 & 322,0 \\
\hline $\mathrm{XM}_{\mathrm{EU}}$ & $-1,861$ & 0,115 & 0,153 & 1,327 & 341,4 \\
\hline $\mathrm{XM}_{\mathrm{Mer}}$ & $-2,100$ & $-2,459$ & $-1,103$ & 0,448 & 36,83 \\
\hline $\mathrm{PI}_{\mathrm{EUA}}$ & $-3,536$ & $-17,999 * *$ & $-2,991 * *$ & 0,166 & 5,113 \\
\hline $\mathrm{PI}_{\mathrm{EU}}$ & $-2,321 * * *$ & $-7,009 *$ & $-1,859^{*}$ & 0,265 & 3,542 \\
\hline $\mathrm{PI}_{\mathrm{Mer}}$ & $-1,750^{*}$ & $-6,645^{*}$ & $-1,789^{*}$ & 0,269 & 3,806 \\
\hline TCRE & $-5,765 * * *$ & $-59,365 * *$ & $-5,439 * * *$ & 0,091 & 1,573 \\
\hline
\end{tabular}

Fonte: Elaboração própria.

Nota: * ${ }^{* *}, * *$ denotam nível de significância a 10\%, 5\% e 1\%, respectivamente. Teste realizado para intercepto e tendência e utilizando o critério AIC modificado para a seleção das defasagens.

Assim, observa-se na Tabela 3 que tanto para uma quebra quanto para duas quebras endógenas o teste de Lee e Strazicich $(2003,2013)$ evidenciou que as exportações de básicos do Mercosul, de manufaturados dos Estados Unidos, Mercosul e União Europeia, semimanufaturados da União Europeia e Produção Industrial dos Estados Unidos são estacionários em nível apesar da existência de uma ou duas quebras estruturais.

Com relação à análise das exportações desagregadas, após realizar os testes de raiz unitária de DF-GLS e Ng-Perron, com as variáveis em primeira diferença, observou-se que a grande maioria dos bens manufaturados exportados agrupados em capítulos da Nomenclatura Comum do Mercosul - NCM, com destino aos EUA não são estacionários, I(1), pelas duas estatísticas de teste empregadas. Como pode se observar na Tabela 4, apenas os setores 16 e 44 (que correspondem aos produtos de preparações de carne, de peixes ou de crustáceos, de moluscos ou de 
outros invertebrados aquáticos, e aos produtos de madeira, carvão vegetal e obras de madeira, de acordo com a nomenclatura oficial), são estacionários na primeira diferença pelas duas estatísticas.

Tabela 3 - Teste de raiz unitária com quebra estrutural

\begin{tabular}{|c|c|c|c|c|c|c|c|}
\hline \multirow[b]{2}{*}{ Variável } & \multirow[b]{2}{*}{ Tipo } & \multicolumn{3}{|c|}{ Uma quebra } & \multicolumn{3}{|c|}{ Duas quebras estruturais } \\
\hline & & Lags & $\begin{array}{c}\text { Estatísti- } \\
\text { ca } t\end{array}$ & $\begin{array}{l}\text { Data da } \\
\text { quebra }\end{array}$ & Lags & $\begin{array}{c}\text { Estatísti- } \\
\quad \text { ca } t\end{array}$ & $\begin{array}{l}\text { Data da } \\
\text { quebra }\end{array}$ \\
\hline $\mathrm{XB}_{\mathrm{Mer}}$ & Break & 9 & $-4,017 * *$ & 2012.01 & 0 & $-7,721 * * *$ & $\begin{array}{l}2008.07 \\
2012.01\end{array}$ \\
\hline $\mathrm{XM}_{\mathrm{EUA}}$ & Break & 12 & $-3,784 * *$ & 2008.10 & 12 & $-5,823 * * *$ & $\begin{array}{l}2003.12 \\
2009.01\end{array}$ \\
\hline $\mathrm{XM}_{\mathrm{MER}}$ & Break & 9 & $-4,733 * * *$ & 2004.10 & 9 & $-5,621 * * *$ & $\begin{array}{l}2004.10 \\
2008.12\end{array}$ \\
\hline $\mathrm{XM}_{\mathrm{UE}}$ & Break & 12 & $-4,645^{* * *}$ & 2004.10 & 1 & $-6,398 * * *$ & $\begin{array}{l}2004.10 \\
2006.06\end{array}$ \\
\hline $\mathrm{XS}_{\mathrm{UE}}$ & Break & 12 & $-4,285 * * *$ & 2006.02 & 12 & $-5,441 * *$ & $\begin{array}{l}2008.04 \\
2010.09\end{array}$ \\
\hline $\mathrm{PI}_{\mathrm{EUA}}$ & Break & 10 & $-3,332^{*}$ & 2008.03 & 11 & $-5,736 * *$ & $\begin{array}{l}2005.08 \\
2008.10\end{array}$ \\
\hline
\end{tabular}

Fonte: Elaboração própria.

Nota: *, **, *** denotam nível de significância a 10\%, 5\% e 1\%, respectivamente. Os valores críticos para uma quebra na tendência ou no nível são reportados em Lee e Strazicich (2013, Tabela 1) e para duas quebras em Lee e Strazicich (2003, Tabela 2).

Porém, um dos fatores que podem justificar esta não estacionariedade das séries de exportações para EUA é a ocorrência de quebra estrutural. Então, utilizou-se o teste de quebra de Lee e Strazicich $(2003,2013)$ para a análise do teste de raiz unitária com quebra estrutural endógena. Neste caso o teste foi realizado para as variáveis em nível.

Como se pode observar na Tabela 5, no teste de Lee e Strazicich apenas os setores 72 e 88 (setor de ferro fundido, ferro e aço, e setor de aeronaves e aparelhos espaciais, e suas partes, respectivamente) apresentaram-se com não estacionários em nível. Assim, para os demais setores pode-se admitir que são estacionários apesar da existência de uma ou duas quebras estruturais. Portanto, para a análise de cointegração via teste de fronteira de Pesaran, Shin e Smith (2001), as exportações dos setores 72 e 88 não serão consideradas, pois não se pode afirmar que os mesmos são integrados de ordem menor que dois. 
Tabela 4 - Teste DF-GLS de raiz unitária, DF-GLS e Ng-Perron, para as exportações brasileiras para os Estados Unidos, variáveis em primeira diferença

\begin{tabular}{l|c|c|c|c|r}
\hline Capítulo NCM & $\begin{array}{c}\text { Estatistica } \\
\text { DF-GLS }\end{array}$ & MZa & MZt & MSB & MPT \\
\hline 16 & $-9,593 * * *$ & $-44,519 * * *$ & $-4,717 * * *$ & 0,105 & 2,047 \\
20 & $-1,828 * *$ & 1,845 & 3,857 & 2,089 & 1042,92 \\
22 & $-1,944$ & $-0,479$ & $-0,420$ & 0,876 & 143,814 \\
28 & $-2,880 *$ & $-0,472$ & $-0,459$ & 0,971 & 173,566 \\
29 & $-2,880 *$ & $-0,472$ & $-0,459$ & 0,971 & 173,566 \\
39 & $-1,490$ & $-0,243$ & $-0,327$ & 1,346 & 332,058 \\
40 & $-2,081$ & $-0,044$ & $-0,051$ & 1,171 & 262,708 \\
44 & $-20,718 * * *$ & $-73,578 * * *$ & $-6,064 * * *$ & 0,082 & 1,243 \\
48 & $-2,714 *$ & $-3,437$ & $-1,310$ & 0,381 & 26,508 \\
68 & $-1,959$ & $-0,296$ & $-0,360$ & 1,216 & 271,350 \\
72 & $-2,115$ & $-1,210$ & $-0,777$ & 0,642 & 75,219 \\
73 & $-1,401$ & $-0,482$ & $-0,451$ & 0,934 & 161,576 \\
84 & $-3,542 * * *$ & $-2,749$ & $-1,172$ & 0,426 & 33,133 \\
85 & $-2,053 * *$ & $-1,623$ & $-0,716$ & 0,441 & 40,825 \\
87 & $-2,647$ & $-0,907$ & $-0,576$ & 0,634 & 77,341 \\
88 & $-2,665$ & $-0,981$ & $-0,696$ & 0,709 & 91,936 \\
\hline
\end{tabular}

Fonte: Elaboração própria.

Nota: *, **, ** denotam nível de significância a 10\%, 5\% e 1\%, respectivamente. Teste realizado para intercepto e tendência e utilizando o critério AIC modificado para a seleção das defasagens. 
Tabela 5 - Teste de raiz unitária com quebra estrutural, variáveis em nível

\begin{tabular}{|c|c|c|c|c|c|c|c|}
\hline \multirow[b]{2}{*}{ Variável } & \multirow[b]{2}{*}{ Tipo } & \multicolumn{3}{|c|}{ Uma quebra } & \multicolumn{3}{|c|}{ Duas quebras estruturais } \\
\hline & & Lags & Estatística $t$ & $\begin{array}{l}\text { Data da } \\
\text { quebra }\end{array}$ & Lags & Estatística $t$ & $\begin{array}{c}\text { Data da } \\
\text { quebra }\end{array}$ \\
\hline 20 & Break & 2 & $-5,871 * * *$ & 2005.01 & 0 & $-15,489 * * *$ & $\begin{array}{l}2006.12 \\
2011.04\end{array}$ \\
\hline 22 & Break & 1 & $-5,161 * * *$ & 2004.02 & 1 & $-5,844 * * *$ & $\begin{array}{l}2006.03 \\
2011.08\end{array}$ \\
\hline 28 & Break & 11 & $-5,234 * * *$ & 2007.02 & 11 & $-6,784 * * *$ & $\begin{array}{l}2007.10 \\
2009.06\end{array}$ \\
\hline 29 & Break & 11 & $-5,234 * * *$ & 2007.02 & 11 & $-6,784 * * *$ & $\begin{array}{l}2007.10 \\
2009.06\end{array}$ \\
\hline 39 & Break & 11 & $-5,077 * * *$ & 2004.08 & 1 & $-6,291 * * *$ & $\begin{array}{l}2002.08 \\
2004.01\end{array}$ \\
\hline 40 & Break & 12 & $-5,210 * * *$ & 2007.07 & 12 & $-6,694 * * *$ & $\begin{array}{l}2003.08 \\
2007.07\end{array}$ \\
\hline 48 & Break & 9 & $-2,556$ & 2007.09 & 11 & $-6,490 * * *$ & $\begin{array}{l}2003.03 \\
2009.01\end{array}$ \\
\hline 68 & Break & 11 & $-4,398 * * *$ & 2003.06 & 11 & $-6,490 * * *$ & $\begin{array}{l}2003.03 \\
2009.01\end{array}$ \\
\hline 72 & Break & 9 & $-2,640$ & 2008.03 & 1 & $-4,985^{*}$ & $\begin{array}{l}2005.09 \\
2009.01\end{array}$ \\
\hline 73 & Break & 1 & $-4,698 * * *$ & 2007.05 & 1 & $-5,744^{* *}$ & $\begin{array}{l}2004.03 \\
2007.07\end{array}$ \\
\hline 84 & Break & 2 & $-3,989 * *$ & 2009.04 & 9 & $-7,319 * * *$ & $\begin{array}{l}2005.09 \\
2009.05\end{array}$ \\
\hline 85 & Break & 7 & $-3,510^{*}$ & 2008.02 & 7 & $-4,881$ & $\begin{array}{l}2005.06 \\
2009.02\end{array}$ \\
\hline 87 & Break & 9 & $-4,029 * *$ & 2009.07 & 9 & $-4,885$ & $\begin{array}{l}2008.08 \\
2011.08\end{array}$ \\
\hline 88 & Break & 9 & $-2,625$ & 2007.03 & 9 & $-4,976$ & $\begin{array}{l}2007.01 \\
2010.05\end{array}$ \\
\hline
\end{tabular}

Fonte: Elaboração própria.

Nota: ***, ** " denotam nível de significância de 1\%, 5\% e 10\%, respectivamente. Os valores críticos para uma quebra na tendência ou no nível são reportados em Lee e Strazicich (2013, Tabela 1) e para duas quebras em Lee e Strazicich (2003, Tabela 2)

Com relação às exportações para o Mercosul, os testes de raiz unitária para as variáveis em primeira diferença evidenciaram que a grande maioria dos bens manufaturados exportados para o Mercosul não são estacionários na primeira diferença. Como se pode observar na Tabela 6, apenas os setores 28 (de produtos químicos inorgânicos; compostos inorgânicos ou orgânicos de metais preciosos, de 
elementos radioativos, de metais de terras raras ou de isótopos), 38 (de produtos diversos das indústrias químicas), 73 (de obras de ferro fundido, ferro ou aço) e 84 (de reatores nucleares, caldeiras, máquinas, aparelhos e instrumentos mecânicos e suas partes) são estacionários na primeira diferença, I(1).

Porém, um dos fatores que podem justificar esta não estacionariedade das séries de exportações para Mercosul é a quebra estrutural. Então, utilizou-se o teste de raiz unitária de Lee e Strazicich $(2003,2013)$. Pode-se observar que para todos os setores que não foram estacionários pelas duas estatísticas em primeira diferença, como consta na Tabela 6, os resultados dos testes de raiz unitária com quebra estrutural evidenciaram que estes setores são estacionários em nível, conforme a Tabela 7. Portanto, as quebras seriam responsáveis por dificultar a análise de estacionariedade das séries nos teste de raiz unitária que não consideram em sua estrutura a ocorrência de quebras.

Tabela 6 - Teste DF-GLS de raiz unitária, DF-GLS e Ng-Perron, para as exportações de manufaturados brasileiras para o Mercosul, variáveis em primeira diferença

\begin{tabular}{c|l|l|l|l|r}
\hline Capítulo NCM & $\begin{array}{c}\text { Estatistica } \\
\text { DF-GLS }\end{array}$ & MZa & MZt & MSB & MPT \\
\hline 27 & $-1,319$ & $-0,182$ & $-0,302$ & 1,654 & 498,810 \\
28 & $-3,709 * * *$ & $-16,775 * * *$ & $-2,881 *$ & 0,171 & 5,525 \\
29 & $-1,962$ & $-0,441$ & $-0,415$ & 0,941 & 164,838 \\
31 & $-1,732$ & $-0,181$ & $-0,191$ & 1,052 & 210,677 \\
38 & $-19,039 * * *$ & $-78,473 * *$ & $-6,263 * * *$ & 0,079 & 1,163 \\
39 & $-2,359$ & $-3,561$ & $-1,309$ & 0,367 & 25,179 \\
40 & $-3,171 * *$ & $-4,253$ & $-1,458$ & 0,342 & 21,421 \\
48 & $-1,846$ & $-0,731$ & $-0,544$ & 0,743 & 103,514 \\
72 & $-2,424$ & 0,6300 & 0,548 & 0,870 & 166,244 \\
73 & $-1,729 *$ & $-6,020 *$ & $-1,731 *$ & 0,287 & 4,082 \\
84 & $-3,639 * * *$ & $-15,375 *$ & $-2,772 *$ & 0,180 & 5,926 \\
85 & $-2,047 * *$ & $-2,672$ & $-1,134$ & 0,424 & 33,379 \\
87 & $-2,078$ & $-2,715$ & $-1,151$ & 0,424 & 33,106 \\
\hline
\end{tabular}

Fonte: Elaboração própria.

Nota: *, **, *** denotam nível de significância a 10\%, 5\% e 1\%, respectivamente. Teste realizado para intercepto e tendência e utilizando o critério AIC modificado para a seleção das defasagens. 
Tabela 7 - Teste de raiz unitária de Lee-Strazicich para as exportações para o Mercosul, variáveis em nível

\begin{tabular}{|c|c|c|c|c|c|c|c|}
\hline \multirow[b]{2}{*}{ Variável } & \multirow[b]{2}{*}{ Tipo } & \multicolumn{3}{|c|}{ Uma quebra } & \multicolumn{3}{|c|}{ Duas quebras estruturais } \\
\hline & & Lags & Estatística $t$ & $\begin{array}{l}\text { Data da } \\
\text { quebra }\end{array}$ & Lags & Estatística $t$ & $\begin{array}{l}\text { Data da } \\
\text { quebra }\end{array}$ \\
\hline 27 & Break & 2 & $-2,859$ & 2004.08 & 1 & $-7,192 * * *$ & $\begin{array}{l}2005.11 \\
2007.07\end{array}$ \\
\hline 29 & Break & 0 & $-8,477^{* * *}$ & 2004.11 & 0 & $-8,952 * * *$ & $\begin{array}{l}2002.10 \\
2008.11\end{array}$ \\
\hline 31 & Break & 12 & $-3,798 * *$ & 2009.10 & 9 & $-5,135^{*}$ & $\begin{array}{l}2004.02 \\
2007.08\end{array}$ \\
\hline 39 & Break & 9 & $-3,824 * *$ & 2004.05 & 9 & $-4,836$ & $\begin{array}{l}2004.03 \\
2005.10\end{array}$ \\
\hline 40 & Break & 11 & $-4,551 * * *$ & 2010.11 & 11 & $-5,746 * *$ & $\begin{array}{l}2003.08 \\
2010.11\end{array}$ \\
\hline 48 & Break & 11 & $-5,041 * * *$ & 2004.10 & 11 & $-5,801 * *$ & $\begin{array}{l}2004.04 \\
2007.01\end{array}$ \\
\hline 72 & Break & 11 & $-3,881 * *$ & 2006.11 & 11 & $-4,956$ & $\begin{array}{l}2003.11 \\
2010.04\end{array}$ \\
\hline 85 & Break & 10 & $-4,213 * *$ & 2004.10 & 11 & $-6,301 * * *$ & $\begin{array}{l}2004.08 \\
2008.03\end{array}$ \\
\hline 87 & Break & 9 & $-4,674 * * *$ & 2004.11 & 9 & $-5,506 * *$ & $\begin{array}{l}2004.02 \\
2012.05\end{array}$ \\
\hline
\end{tabular}

Fonte: Elaboração própria..

Nota: **, **, * denotam nível de significância de 1\%, 5\% e 10\%, respectivamente. Os valores críticos para uma quebra na tendência ou no nível são reportados em Lee e Strazicich (2013, Tabela 1) e para duas quebras em Lee e Strazicich (2003, Tabela 2)

Para as exportações brasileiras com destino à União Europeia, verificou-se que os setores 9 (de produtos de café, chá, mate e especiarias), 10 (de cereais) e 27 (de combustíveis minerais, óleos minerais e produtos da sua destilação; matérias betuminosas; ceras minerais) são estacionários em primeira diferença, conforme a Tabela 8. Já para o teste de raiz unitária de Lee e Strazicich (2003, 2013), apenas o setor 12 (de sementes e frutos oleaginosos; grãos, sementes e frutos diversos; plantas industriais ou medicinais; palhas e forragens) não seria estacionário em nível, conforme a Tabela 9. 
Tabela 8 - Teste DF-GLS de raiz unitária, DF-GLS e Ng-Perron, para as exportações de produtos básicos brasileiras para a União Europeia, variáveis em primeira diferença

\begin{tabular}{c|l|l|l|l|r}
\hline Capítulo NCM & $\begin{array}{c}\text { Estatística } \\
\text { DF-GLS }\end{array}$ & MZa & MZt & MSB & MPT \\
\hline 2 & $-3,561 * * *$ & $-5,369$ & $-1,599$ & 0,297 & 16,850 \\
8 & $-1,145$ & 0,001 & 0,001 & 1,270 & 308,646 \\
9 & $-5,414 * * *$ & $-24,143 * * *$ & $-3,472 * * *$ & 0,143 & 3,783 \\
10 & $-1,986 * *$ & $-18,966 * *$ & $-2,966 * *$ & 0,156 & 5,500 \\
12 & $-1,633$ & $-0,322$ & $-0,382$ & 1,188 & 258,624 \\
23 & $-2,285$ & 0,066 & 0,105 & 1,585 & 477,580 \\
24 & $-2,168$ & $-0,449$ & $-0,472$ & 1,051 & 201,613 \\
26 & $-1,801$ & $-0,681$ & $-0,522$ & 0,765 & 109,741 \\
27 & $-24,250 * * *$ & $-63,305 * * *$ & $-5,626 * * *$ & 0,088 & 1,439 \\
\hline
\end{tabular}

Fonte: Elaboração própria.

Nota: *, **, ** denotam nível de significância a 10\%, 5\% e 1\%, respectivamente. Teste realizado para intercepto e tendência e utilizando o critério AIC modificado para a seleção das defasagens.

Tabela 9 - Teste de raiz unitária de Lee-Strazicich para as exportações para a União Europeia, variáveis em nível

\begin{tabular}{|c|c|c|c|c|c|c|c|}
\hline \multirow[b]{2}{*}{ Variável } & \multirow[b]{2}{*}{ Tipo } & \multicolumn{3}{|c|}{ Uma quebra } & \multicolumn{3}{|c|}{ Duas quebras estruturais } \\
\hline & & Lags & Estatística $t$ & $\begin{array}{l}\text { Data da } \\
\text { quebra }\end{array}$ & Lags & Estatística $t$ & $\begin{array}{c}\text { Data da } \\
\text { quebra }\end{array}$ \\
\hline 2 & Break & 11 & $-4,807 * * *$ & 2008.02 & 11 & $-6,336 * * *$ & $\begin{array}{l}2007.12 \\
2010.07\end{array}$ \\
\hline 8 & Break & 7 & $-5,098 * * *$ & 2006.11 & 7 & $-6,637 * * *$ & $\begin{array}{l}2003.01 \\
2009.01\end{array}$ \\
\hline 12 & Break & 11 & $-2,567$ & 2003.07 & 12 & $-4,000$ & $\begin{array}{l}2002.05 \\
2010.01\end{array}$ \\
\hline 23 & Break & 11 & $-2,891$ & 2005.09 & 12 & $-5,466 * *$ & $\begin{array}{l}2004.08 \\
2007.12\end{array}$ \\
\hline 24 & Break & 0 & $-8,641 * * *$ & 2011.11 & 0 & $-9,290 * * *$ & $\begin{array}{l}2009.06 \\
2012.01\end{array}$ \\
\hline 26 & Break & 12 & $-4,128 * *$ & 2010.08 & 12 & $-5,092 *$ & $\begin{array}{l}2005.04 \\
2010.10\end{array}$ \\
\hline
\end{tabular}

Fonte: Elaboração própria.

Nota: ***, **" " denotam nível de significância de 1\%, $5 \%$ e 10\%, respectivamente. Os valores críticos para uma quebra na tendência ou no nível são reportados em Lee e Strazicich (2013, Tabela 1) e para duas quebras em Leee e Strazicich (2003, Tabela 2) 
Com relação à análise de cointegração de acordo com a equação (6), as Tabelas 10 e 11 apresentam os resultados dos testes de cointegração baseado no modelo ARDL, Teste de Fronteira de cointegração de Pesaran, Shin e Smith (2001), para as séries de exportações agregadas e desagregadas. Pode-se observar na Tabela 10 que as exportações de produtos básicos, manufaturados e semimanufaturados para o Mercosul cointegrou com os modelos para volatilidade de 3, 6 e 12 meses. Neste caso, o valor da estatística F, F Fss, para a hipótese nula de não cointegração foi maior que o valor crítico estabelecido em Pesaran, Shin e Smith (2001) com significância de 10\% e 5\%. Para os casos em que se rejeitou a hipótese de não cointegração também se verificou a cointegração pela abordagem de Banerjee, Dolado e Mestre (1998) que considera a estatística t e o sinal da variável de correção de erros para a equação (6). Assim, o valor da estatística t do coeficiente da variável de correção de erros, ECM, é comparado com o valor crítico estabelecido em Banerjee, Dolado e Mestre (1998, p. 276) considerando o tamanho da amostra e número de regressos. Uma questão importante nesta análise de cointegração de Pesaran, Shin e Smith (2001) é que os modelos estimados não apresentem correlação serial dos resíduos. Desta forma, na Tabela 10 observa-se na coluna denominada Autocorr que os modelos não apresentaram correlação serial de resíduos. Portanto, quanto às exportações brasileiras para o Mercosul há evidência estatística de relação de longo prazo entre as exportações, volatilidade do câmbio real efetivo, renda externa e preços relativos ou taxa de câmbio real efetiva.

Para as exportações com destino aos Estados Unidos foi verificada cointegração apenas para os produtos semimanufaturados e manufaturados, sendo que para os produtos manufaturados encontra-se cointegração para as três versões de volatilidade e para os produtos semimanufaturados apenas para as volatilidades de três e seis meses. Por fim, para a União Europeia apenas nas exportações de semimanufaturados é que se encontrou a cointegração com as volatilidades trimestral e semestral.

Como pode ser observado na primeira coluna da Tabela 10, as participações das exportações de básicos, manufaturados e semimanufaturados para os três destinos sob análise, observa-se que para as exportações brasileiras com destino aos Estados Unidos e Mercosul no ano de 2014, a maior parte foi de manufaturados, 54\% e 72\%, respectivamente. Para a União Europeia, as exportações brasileiras de produtos básicos representaram 52\% no ano de 2014. Desta forma, para a análise das exportações desagregadas a seis dígitos da NCM (e organizadas em capítulos da NCM), selecionou-se estes setores mais representativos para as exportações brasileira com destino aos Estados Unidos, Mercosul e União Europeia. Nesta análise, o intuito é verificar se a questão do viés de agregação pode alterar os resultados de cointegração. 


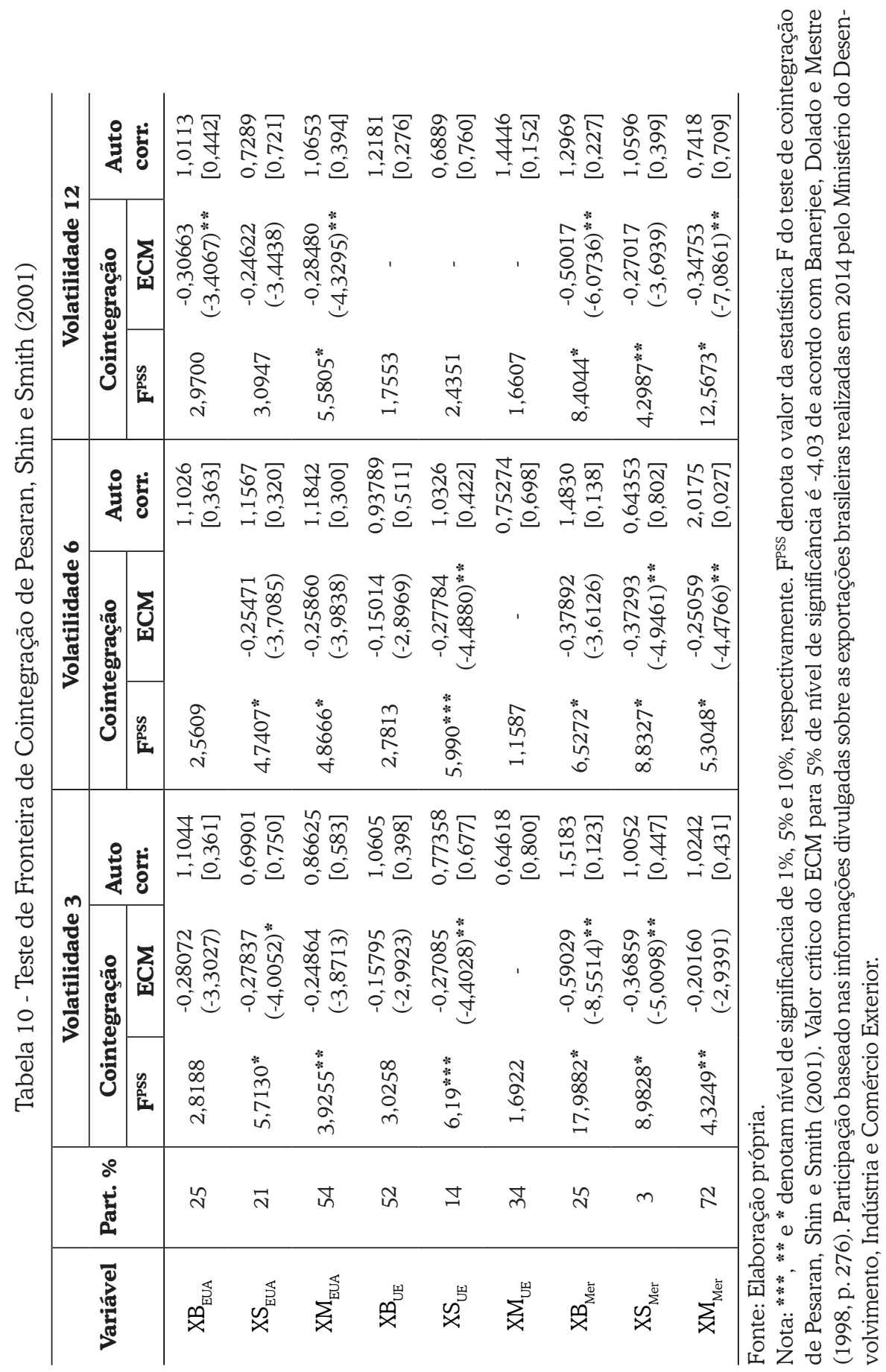




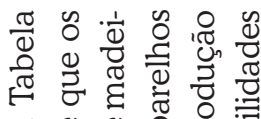

๘

ब त्र की की

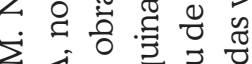

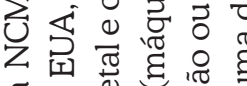

ช 000 in

\%

总

ठี

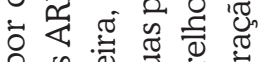

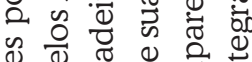

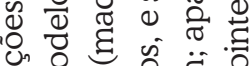

ช్త

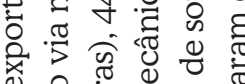

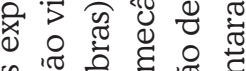

水

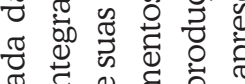

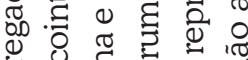

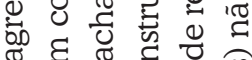

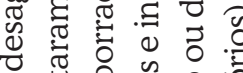

ช

$\triangleq$ లి

营施莡

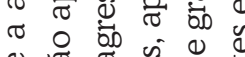

ญ :

营

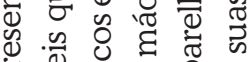

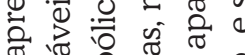

च 䓠

๘

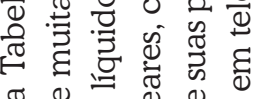

¿

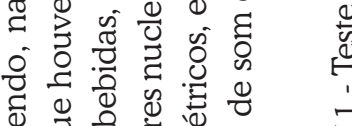

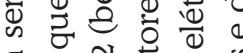

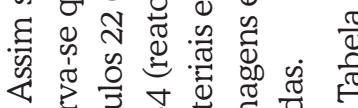

忢

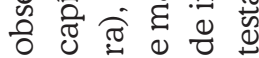

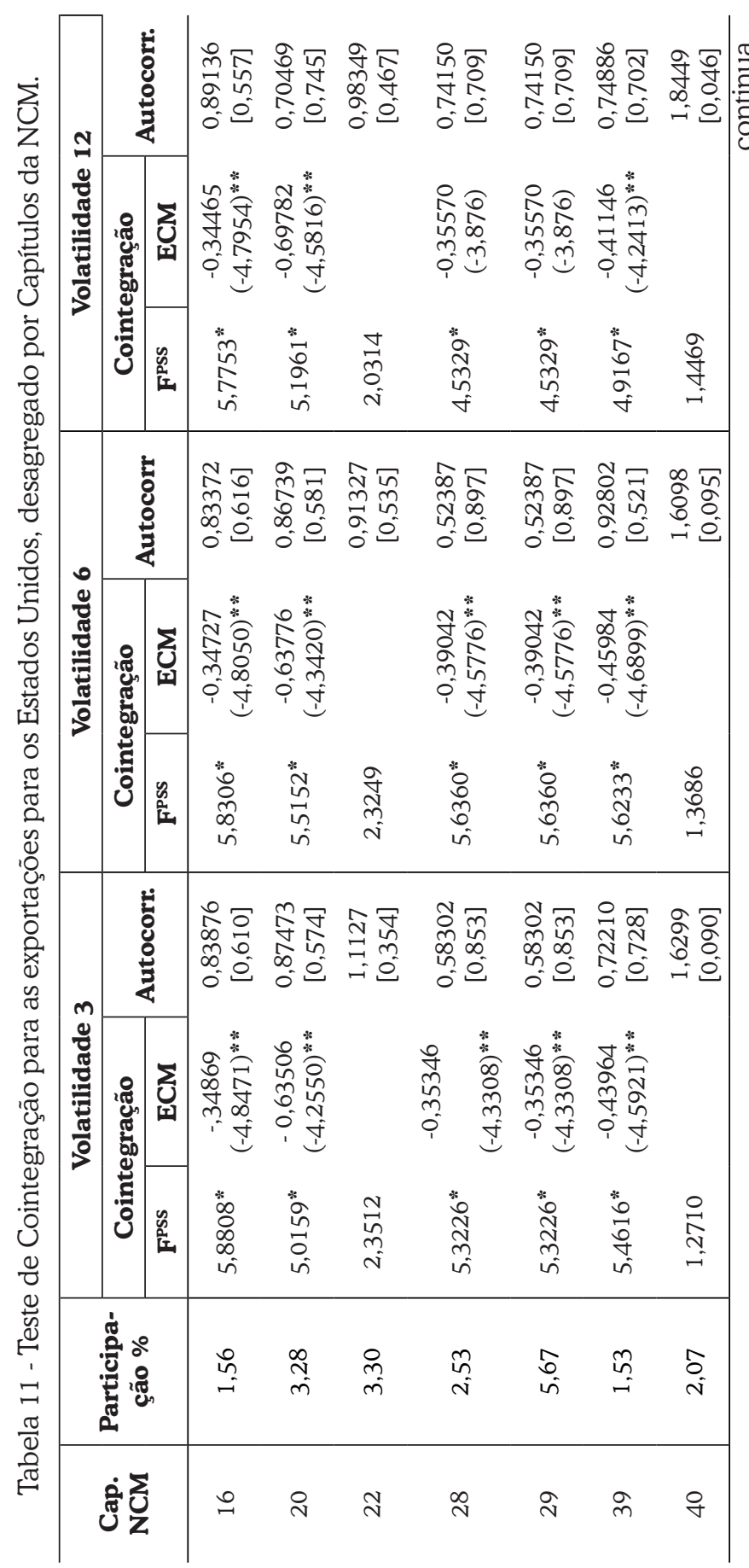




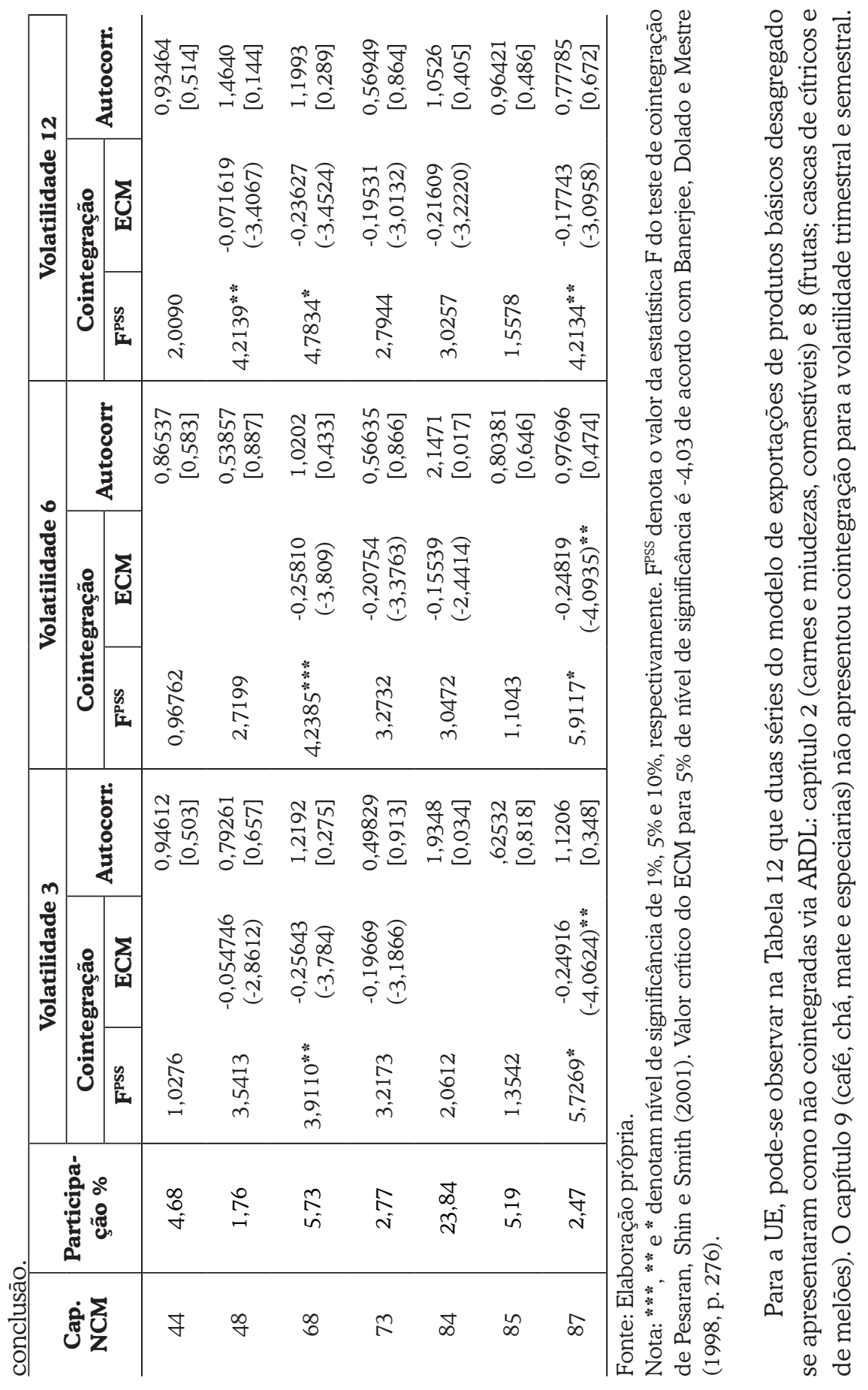




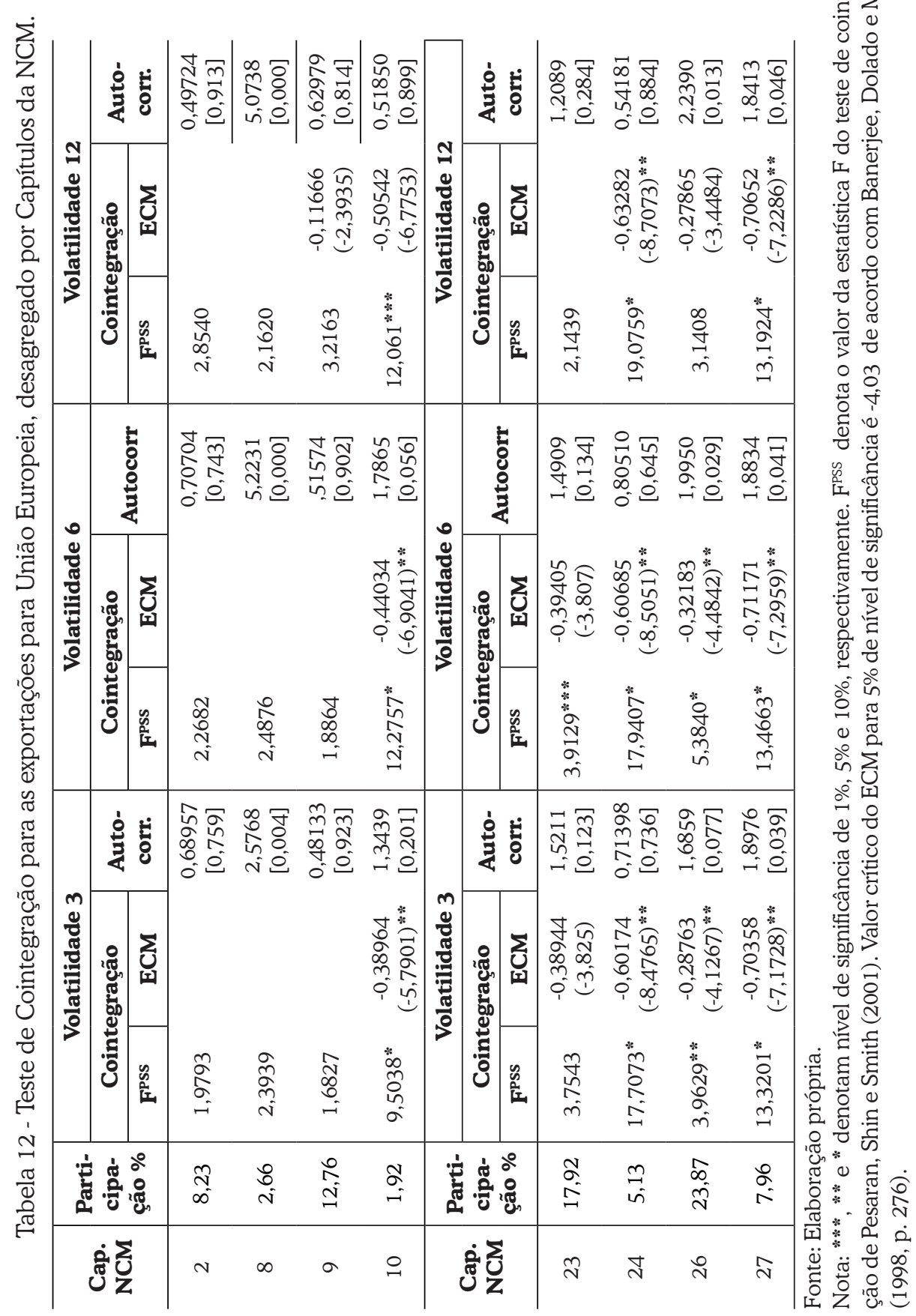




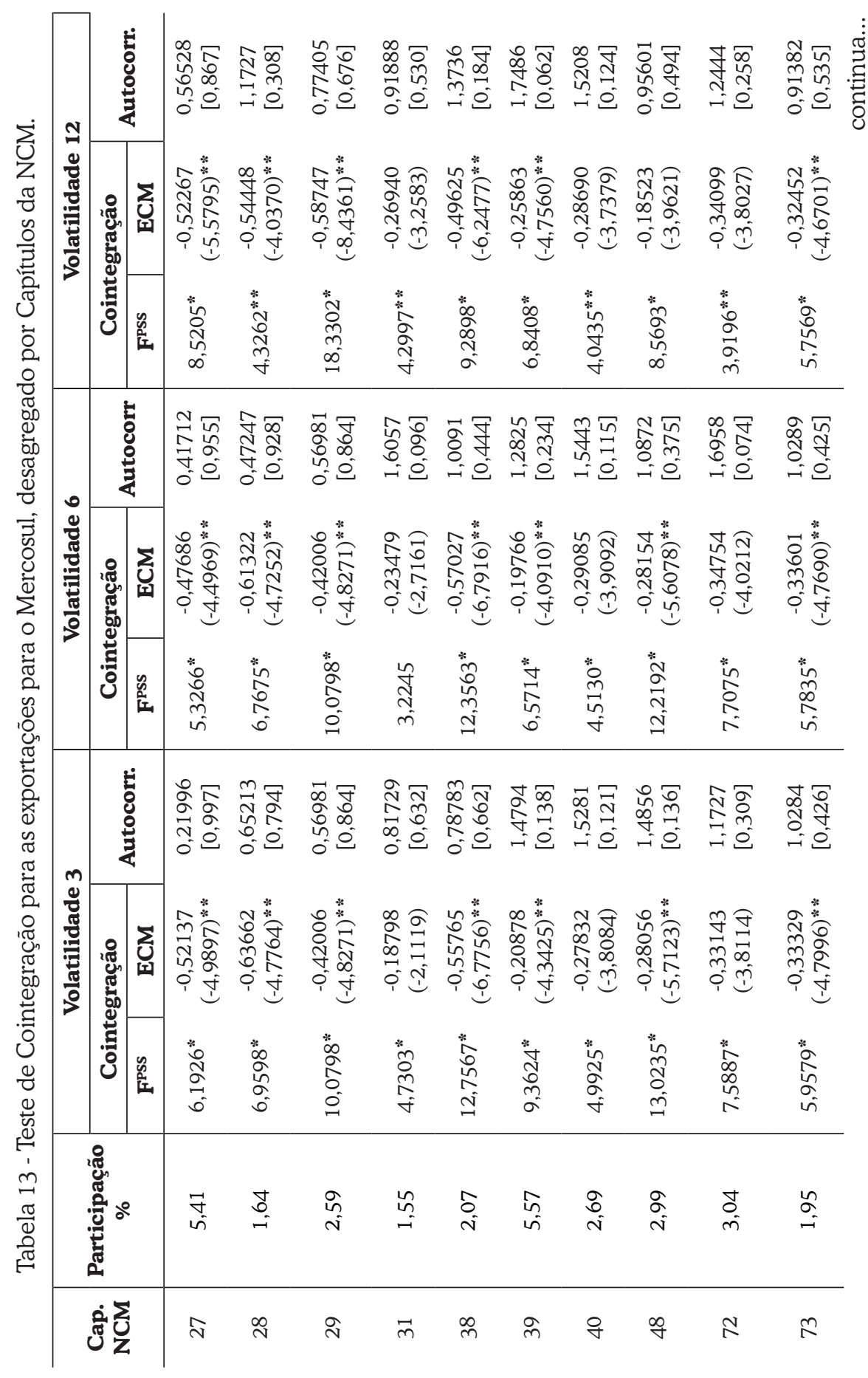




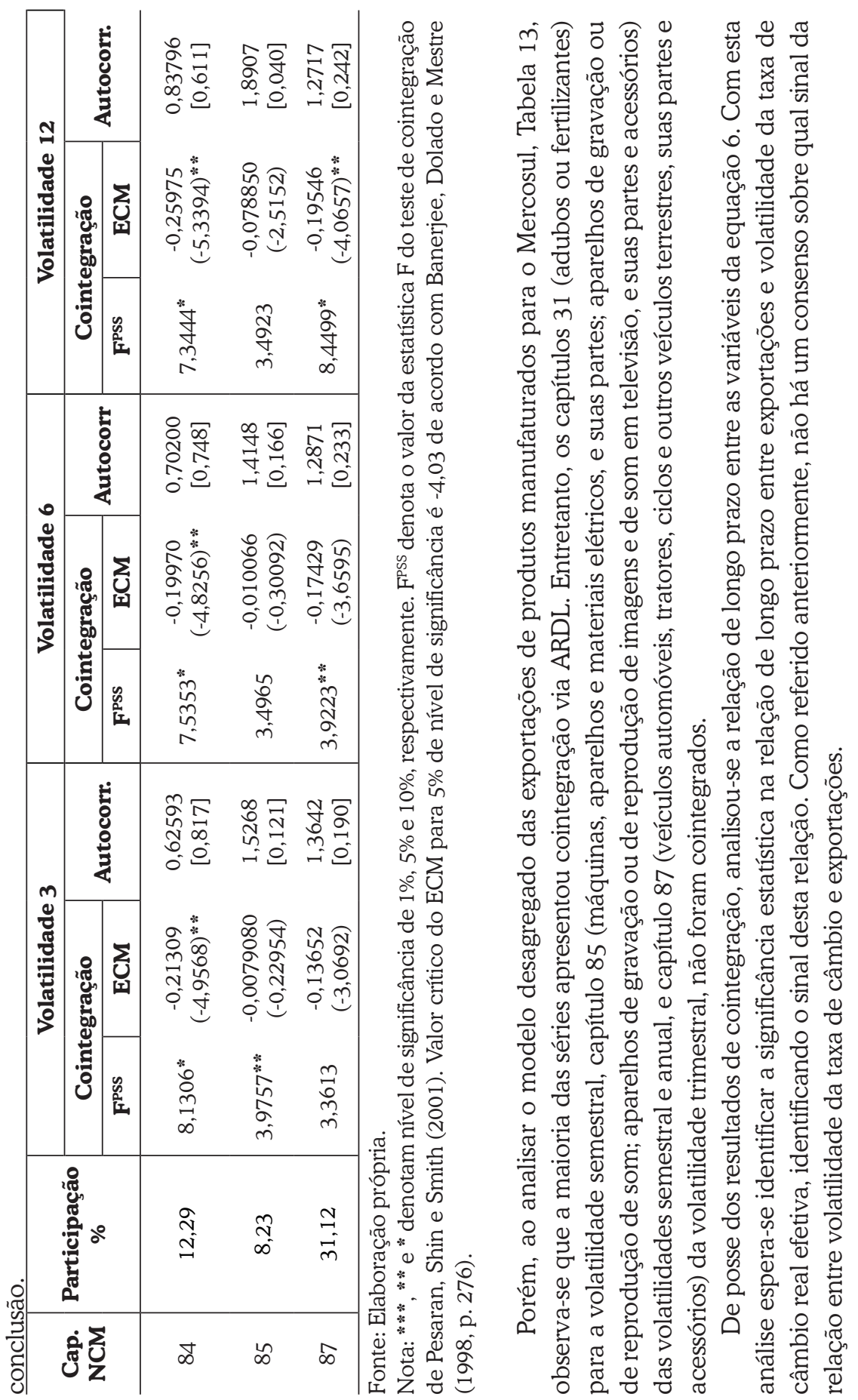


Pode-se observar na Tabela 14 que para as exportações com destino aos Estados Unidos as volatilidades para o período de três e doze meses foram estatisticamente significativas e apresentaram sinal negativo para os produtos semimanufaturados e manufaturados, respectivamente. Percebe-se, assim, que nesta análise das exportações agregadas não ocorreu a constância da periodicidade da volatilidade em uma relação de longo prazo. Entretanto, para os dois casos o sinal foi negativo, evidenciando que quanto maior a incerteza com relação ao câmbio real efetivo, maior o impacto negativo sobre as exportações para os Estados Unidos.

Tabela 14 - Relação de longo prazo para o modelo agregado

\begin{tabular}{|c|c|c|c|c|c|c|c|}
\hline \multirow[b]{2}{*}{$\begin{array}{l}\text { Paí- } \\
\text { ses }\end{array}$} & \multirow[b]{2}{*}{$\begin{array}{l}\text { Volati- } \\
\text { lidade }\end{array}$} & \multirow[b]{2}{*}{$\begin{array}{l}\text { Agrega- } \\
\text { do }\end{array}$} & \multirow[b]{2}{*}{ ARDL } & \multicolumn{4}{|c|}{ Coeficientes de longo prazo } \\
\hline & & & & Constante & PI & TCRE & VOL \\
\hline \multirow{9}{*}{ 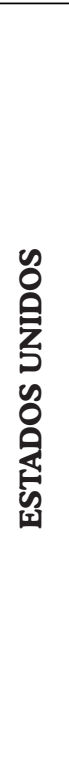 } & \multirow{3}{*}{ Vol. 3} & Básico & $(5,0,0,2)$ & 12,2721 & $-0,069671$ & $1,6930^{*}$ & $-0,93651$ \\
\hline & & $\begin{array}{l}\text { Semima- } \\
\text { nufatura- } \\
\text { do }\end{array}$ & $(3,1,0,6)$ & 11,3132 & 1,9013 & $-0,085207$ & $-15,2207^{* *}$ \\
\hline & & $\begin{array}{l}\text { Manufa- } \\
\text { turado }\end{array}$ & $(3,1,0,2)$ & 5,5528 & $3,4250 * * *$ & $-0,16789$ & $-0,0045003$ \\
\hline & \multirow{4}{*}{ Vol. 6} & Básico & - & - & - & - & - \\
\hline & & $\begin{array}{l}\text { Semima- } \\
\text { nufatura- } \\
\text { do }\end{array}$ & $(3,1,0,2)$ & 9,3891 & 2,1724 & 0,053704 & $-7,7264$ \\
\hline & & $\begin{array}{l}\text { Manufa- } \\
\text { turado }\end{array}$ & $(3,0,6,2)$ & $9,8519 * * *$ & $2,7900 * * *$ & $-0,47072^{* *}$ & $-1,7963$ \\
\hline & & Básico & $(5,0,0,2)$ & 8,8369 & 0,41465 & 1,1037 & 3,1035 \\
\hline & \multirow[t]{2}{*}{ Vol. 12} & $\begin{array}{l}\text { Semima- } \\
\text { nufatura- } \\
\text { do }\end{array}$ & $(3,1,0,0)$ & $-2,0309$ & $3,7859 * * *$ & 0,77949 & 0,45224 \\
\hline & & $\begin{array}{l}\text { Manufa- } \\
\text { turado }\end{array}$ & $(3,0,3,2)$ & $9,0070 * * *$ & $2,8752 * * *$ & $0,86276^{* *}$ & $-4,4839 * * *$ \\
\hline
\end{tabular}




\begin{tabular}{|c|c|c|c|c|c|c|c|}
\hline \multirow[b]{2}{*}{$\begin{array}{l}\text { Paí- } \\
\text { ses }\end{array}$} & \multirow[b]{2}{*}{$\begin{array}{l}\text { Volati- } \\
\text { lidade }\end{array}$} & \multirow[b]{2}{*}{$\begin{array}{c}\text { Agrega- } \\
\text { do }\end{array}$} & \multirow[b]{2}{*}{ ARDL } & \multicolumn{4}{|c|}{ Coeficientes de longo prazo } \\
\hline & & & & Constante & PI & TCRE & VOL \\
\hline \multirow{9}{*}{ 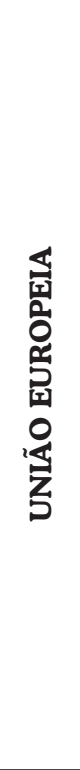 } & \multirow{3}{*}{ Vol. 3} & Básico & - & - & - & - & - \\
\hline & & $\begin{array}{l}\text { Semima- } \\
\text { nufatura- } \\
\text { do }\end{array}$ & $(5,0,1,0)$ & $6,9453^{*}$ & 1,5023 & $1,2728 * * *$ & $-1,6728$ \\
\hline & & $\begin{array}{c}\text { Manufa- } \\
\text { turado }\end{array}$ & - & - & - & - & - \\
\hline & \multirow{3}{*}{ Vol. 6} & Básico & - & - & - & - & - \\
\hline & & $\begin{array}{l}\text { Semima- } \\
\text { nufatura- } \\
\text { do }\end{array}$ & $(5,0,0,0)$ & $7,4179 * *$ & 1,4307 & $1,2419 * * *$ & $-1,1459$ \\
\hline & & $\begin{array}{c}\text { Manufa- } \\
\text { turado }\end{array}$ & - & - & - & - & - \\
\hline & & Básico & - & - & - & - & - \\
\hline & \multirow[t]{2}{*}{ Vol. 12} & $\begin{array}{l}\text { Semima- } \\
\text { nufatura- } \\
\text { do }\end{array}$ & - & - & - & - & - \\
\hline & & $\begin{array}{c}\text { Manufa- } \\
\text { turado }\end{array}$ & - & - & - & - & - \\
\hline \multirow{9}{*}{ 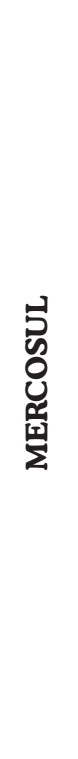 } & \multirow{3}{*}{ Vol. 3} & Básico & $(1,1,0,0)$ & $13,6177 * * *$ & $1,5580 * * *$ & $-0,0516$ & $1,7445 * *$ \\
\hline & & $\begin{array}{l}\text { Semima- } \\
\text { nufatura- } \\
\text { do }\end{array}$ & $(2,1,0,3)$ & $13,0422 * *$ & 1,0174 &,- 074307 & $-15,057 * *$ \\
\hline & & $\begin{array}{c}\text { Manufa- } \\
\text { turado }\end{array}$ & $(12,8,0,5)$ & $10,3448 * * *$ & $2,2818 * * *$ & $-0,052828$ & $-11,918 * * *$ \\
\hline & \multirow{4}{*}{ Vol. 6} & Básico & $(10,1,4,2)$ & $16,9668 * * *$ & 0,55410 & 0,29780 & $-2,9258^{*}$ \\
\hline & & $\begin{array}{l}\text { Semima- } \\
\text { nufatura- } \\
\text { do }\end{array}$ & $(2,1,0,1)$ & $13,0383 * * *$ & 0,92257 & 0,020379 & $-8,6607 * * *$ \\
\hline & & $\begin{array}{l}\text { Manufa- } \\
\text { turado }\end{array}$ & $(10,1,0,0)$ & $9,4446 * * *$ & $2,2624 * * *$ & 0,14290 & $-3,8451 * * *$ \\
\hline & & Básico & $(2,0,0,6)$ & $14,2205 * *$ & $1,4743 * * *$ & $-0,50367$ & 1,4905 \\
\hline & \multirow[t]{2}{*}{ Vol. 12} & $\begin{array}{l}\text { Semima- } \\
\text { nufatura- } \\
\text { do }\end{array}$ & $(2,1,0,0)$ & $8,3164 * * *$ & 1,9953 & 0,66531 & $-2,8521$ \\
\hline & & $\begin{array}{l}\text { Manufa- } \\
\text { turado }\end{array}$ & $(10,0,0,3)$ & $5,9626 * * *$ & $3,5435 * * *$ & 0,021824 & $-1,7742$ \\
\hline
\end{tabular}

Fonte: Elaboração própria.

Nota: ***, ** e denotam nível de significância de 1\%, 5\% e 10\%, respectivamente. 
Com relação às exportações para a União Europeia, a volatilidade não foi estatisticamente significativa na análise de longo prazo, conforme a Tabela 14. Neste caso, apesar de haver um vetor de cointegração para produtos semimanufaturados nas volatilidades de três e seis meses, não existiria estatisticamente importância desta variável sobre as exportações para a União Europeia.

Com relação às exportações para o Mercosul, tem-se que apenas na variável dos produtos básicos o sinal para a volatilidade trimestral muda de positivo para negativo quando se emprega a volatilidade de seis meses. Para os produtos semimanufaturados e manufaturados apenas as volatilidades trimestral e semestral são estatisticamente significativas e apresentam o sinal negativo. Então, as exportações brasileiras para o Mercosul reagiriam negativamente ao aumento da incerteza cambial, conforme a Tabela 14 .

Com relação à análise desagregada, por capítulos da NCM, a Tabela 15 apresenta os resultados dos coeficientes de longo para os modelos que cointegraram, conforme as Tabelas 11, 12 e 13. Para as exportações com destino para os Estados Unidos, o coeficiente de longo prazo para a variável volatilidade foi estatisticamente significativo apenas para os capítulos 48 (papeis e cartões, obras de pasta de celulose, de papel ou de cartão) como volatilidade para três meses, 68 (obras de pedra, gesso, cimento, amianto, mica ou de matérias semelhantes) com volatilidade para doze meses e 87 (veículos automóveis, tratores, ciclos e outros veículos terrestres, suas partes e acessórios) para volatilidade para três e seis meses.

Quanto ao sinal do coeficiente de volatilidade, foi positivo para os capítulos 68 e 87 evidenciando que o aumento da volatilidade tende a impulsionar as exportações; e negativo para o capítulo 48, em que o aumento da volatilidade deprime as exportações deste capítulo com destino aos Estados Unidos (Tabela 15). Estes resultados diferem dos encontrados para a análise agregada (Tabela 14), pois para o total dos produtos manufaturados apenas o coeficiente da volatilidade para doze meses foi significativo e apresentou o sinal negativo, de tal forma que, como afirmam Bahmani-Oskooee e Hegerty (2007), os resultados mais desagregados tendem a representar melhor o impacto da volatilidade sobre o fluxo de comércio.

Quanto à União Europeia, nota-se pela Tabela 14 que apenas para os produtos semimanufaturados é que as volatilidades trimestral e semestral se apresentaram significativas. Além deste fato, pode-se observar que no longo prazo a volatilidade cambial apresentaria sinal negativo, o que confirma a afirmação de alguns dos autores apresentados na revisão bibliográfica deste trabalho. Entretanto, a Tabela 15 evidencia que apenas o capítulo 27 (combustíveis minerais, óleos minerais e produtos da sua destilação; matérias betuminosas; ceras minerais) não apresentaria significância no longo prazo. Com relação aos demais capítulos, observa-se que todos os coeficientes de volatilidade que apresentaram significativos 
no longo prazo apresentam sinal negativo, excluindo-se o coeficiente da volatilidade para doze meses do capítulo 24, que apresentou sinal positivo.

Já nas exportações para o Mercosul, para a maioria dos capítulos referentes a produtos manufaturados que cointegraram (Tabela 11) verificou-se a significância estatística da volatilidade para a relação de longo prazo entre exportações e volatilidade (Tabela 15). Para a volatilidade calculada para o intervalo de três meses, dos doze capítulos que cointegraram, em oito observou-se a significância estatística da volatilidade, sendo que sete apresentaram o sinal negativo, tal que as exportações destes setores são afetadas negativamente com o aumento das incertezas do câmbio, e um apresentou sinal positivo (capítulo 27, de combustíveis minerais, óleos minerais e produtos da sua destilação; matérias betuminosas; ceras minerais). Estes resultados se mantêm em termos de significância estatística e sinal quando se emprega a volatilidade calculada para um período de seis e doze meses. Neste caso, quando se considera a análise agregada por fator agregado (básicos, semimanufaturados e manufaturados), observa-se na Tabela 13 que para os manufaturados apenas a volatilidade de três meses é que seria estatisticamente significativa. Entretanto, esta análise agregada não diverge quando o sinal da variável volatilidade para a análise de longo prazo apresentou um sinal negativo. 
Tabela 15 - Coeficientes de longo prazo em uma abordagem desagregada

\begin{tabular}{|c|c|c|c|c|c|c|c|}
\hline \multirow[b]{2}{*}{$\begin{array}{c}\text { Paí- } \\
\text { ses }\end{array}$} & \multirow[b]{2}{*}{$\begin{array}{l}\text { Cap. } \\
\text { NCM }\end{array}$} & \multicolumn{2}{|c|}{ Volatilidade 3} & \multicolumn{2}{|c|}{ Volatilidade 6} & \multicolumn{2}{|c|}{ Volatilidade 12} \\
\hline & & $\begin{array}{c}\text { Coeficien- } \\
\text { te da vola- } \\
\text { tilidade }\end{array}$ & ARDL & $\begin{array}{c}\text { Coeficien- } \\
\text { te da vola- } \\
\text { tilidade }\end{array}$ & ARDL & $\begin{array}{c}\text { Coeficien- } \\
\text { te da vola- } \\
\text { tilidade }\end{array}$ & ARDL \\
\hline \multirow{8}{*}{ 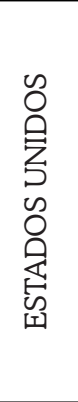 } & 16 & 29,7635 & $(7,0,0,0)$ & 9,8515 & $(7,0,0,0)$ & 5,2843 & $(7,0,0,0)$ \\
\hline & 20 & 2,4248 & $(4,0,0,0)$ & $6,4550^{*}$ & $(4,0,0,0)$ & 4,7331 & $(4,0,0,0)$ \\
\hline & 28 & $-4,4852$ & $(3,0,2,1)$ & $-2,1704$ & $(3,0,0,2)$ & $-0,34706$ & $(3,0,3,1)$ \\
\hline & 29 & $-4,4852$ & $(3,0,2,1)$ & $-2,1704$ & $(3,0,0,2)$ & $-0,34706$ & $(3,0,3,1)$ \\
\hline & 39 & $-2,9257$ & $(3,1,0,2)$ & $-4,4470$ & $(3,2,7,2)$ & 6,9144 & $(3,1,2,2)$ \\
\hline & 48 & $-16,7761 * *$ & $(5,1,0,0)$ & - & - & $-5,5960$ & $(5,1,1,0)$ \\
\hline & 68 & 0,48027 & $(3,0,0,0)$ & $-1,2114$ & $(3,0,0,0)$ & $22,8038^{*}$ & $(3,0,1,5)$ \\
\hline & 87 & $13,6296 * * *$ & $(5,1,3,0)$ & $7,5516 * * *$ & $(5,1,1,0)$ & $-4,2519$ & $(5,1,3,0)$ \\
\hline \multirow{5}{*}{ 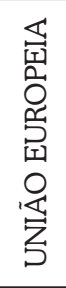 } & 10 & $-103,9434^{* *}$ & $(3,6,4,2)$ & $-22,4191$ & $(1,2,4,0)$ & $-67,6340$ & $(1,2,4,3)$ \\
\hline & 23 & - & - & $-3,2883 * *$ & $(12,0,10,2)$ & - & - \\
\hline & 24 & 3,1115 & $(1,0,0,0)$ & 1,9940 & $(1,0,0,0)$ & $5,4641 * * *$ & $(1,0,2,0)$ \\
\hline & 26 & $-1,0432$ & $(12,0,2,5)$ & $-6,3791^{*}$ & $(12,0,2,5)$ & - & - \\
\hline & 27 & 23,1745 & $(2,0,0,0)$ & 33,3390 & $(2,0,0,0)$ & $-21,3904$ & $(2,0,0,0)$ \\
\hline \multirow{13}{*}{ 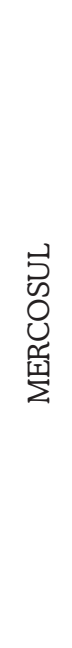 } & 27 & $14,3541 * *$ & $(3,4,0,0)$ & 1,4034 & $(3,0,0,0)$ & $21,9580 * *$ & $(2,0,8,2)$ \\
\hline & 28 & $-12,4786 * * *$ & $(4,1,6,0)$ & $-6,6557^{* *}$ & $(4,1,3,0)$ & $-0,86212$ & $(4,0,6,0)$ \\
\hline & 29 & $-6,1525 * * *$ & $(3,1,0,0)$ & $-6,1525 * *$ & $(3,1,0,0)$ & $-3,8232^{* *}$ & $(1,1,0,0)$ \\
\hline & 31 & $-25,6313$ & $(6,2,1,5)$ & - & - & 24,0632 & $(6,3,7,4)$ \\
\hline & 38 & $-8,1799 * * *$ & $(2,1,5,0)$ & $-4,5987 * * *$ & $(2,1,3,0)$ & $-2,8839 * *$ & $(2,0,0,1)$ \\
\hline & 39 & $-11,1172 * * *$ & $(2,1,2,0)$ & $-7,5119 * * *$ & $(3,1,0,0)$ & $-5,6117 * * *$ & $(2,1,2,0)$ \\
\hline & 40 & $-4,3049$ & $(5,8,1,3)$ & $-2,6529$ & $(5,8,0,3)$ & $-0,014030$ & $(5,8,0,3)$ \\
\hline & 48 & $-11,9663 * * *$ & $(3,0,5,0)$ & $-6,9197 * * *$ & $(4,0,3,0)$ & $-5,6325^{*}$ & $(3,0,4,0)$ \\
\hline & 72 & $-20,4017^{* * *}$ & $(5,5,5,0)$ & $-11,4779 * * *$ & $(5,5,3,0)$ & $-3,0874$ & $(7,1,0,0)$ \\
\hline & 73 & 3,0189 & $(2,0,0,0)$ & 1,9557 & $(2,0,0,0)$ & $-1,1202$ & $(2,0,0,0)$ \\
\hline & 84 & $-17,5108 * * *$ & $(2,5,5,0)$ & $-9,4035^{* * *}$ & $(2,5,2,0)$ & $-5,7873 * * *$ & $(1,4,4,0)$ \\
\hline & 85 & $-35,0404$ & $(4,1,8,0)$ & - & - & - & - \\
\hline & 87 & - & - & $-2,5471$ & $(7,7,1,5)$ & $-14,5075 * *$ & $(3,6,0,2)$ \\
\hline
\end{tabular}

Fonte: Elaboração própria.

Nota: ***, ** e denotam nível de significância de 1\%, 5\% e 10\%, respectivamente. 
Portanto, com relação à análise agregada por fator (produtos básicos, manufaturados e semimanufaturados) e desagregada por capítulos da NCM, os resultados reportados nas Tabela 14 e 15, de um impacto negativo da volatilidade sobre as exportações, são condizentes com os trabalhos retratados no Quadro 1.

\section{Considerações Finais}

O presente trabalho teve como objetivo analisar o efeito que a volatilidade da taxa de câmbio sobre as exportações de produtos brasileiros, considerando para isto os três maiores parceiros comerciais do Brasil. A análise foi feita, inicialmente, agregando as informações de exportações por fator agregado, ou seja, sobre os produtos básicos, semimanufaturados e manufaturados. Após esta investigação, fez-se uma análise dos dados desagregados a seis dígitos da NCM. Para isso, utilizou-se o modelo de cointegração baseado no teste de fronteira de Pesaran, Shin e Smith (2001) que requer que as variáveis dos modelos sejam de ordem de integração menor que dois. A definição de volatilidade empregada foi baseada no desvio padrão da taxa de câmbio real efetiva para um intervalo de três, seis e doze meses.

Sendo assim, na análise agregada identificou-se que, para as exportações para os Estados Unidos, apesar de se ter verificado a cointegração entre exportações, renda externa, volatilidade e câmbio real efetivo para os produtos manufaturados e semimanufaturados, observou-se nas estimações das equações de longo prazo para os modelos cointegrados que apenas a volatilidade de três meses para os semimanufaturados e volatilidade de doze meses para os manufaturados é que obtiveram relevância estatística e apresentaram sinal negativo. Portanto, para as exportações brasileiras para os Estados Unidos, no período em estudo, há pouca evidência da importância da volatilidade cambial na determinação do fluxo de comércio, como reportado também por Bahmani-Oskooee, Harvey e Hegerty (2013).

Nesta mesma análise agregada para a União Europeia, as evidências empíricas da importância da volatilidade são ainda menores que as encontradas para os Estados Unidos. Isso ocorreu pois apenas se verificou a cointegração para os produtos semimanufaturados e o coeficiente de longo prazo da volatilidade para esta categoria de produtos não foi estatisticamente significativo.

Entretanto, estes resultados observados para os Estados Unidos e União Europeia se invertem na análise das informações agregados para o Mercosul. Assim, para todos os níveis de agregação das exportações (básicos, semimanufaturados e manufaturados) houve evidência de cointegração para as três medidas de volatilidade empregadas. E na análise da relação de longo prazo, observou-se que volatilidade é estatisticamente significativa para as medidas de volatilidades de três 
e seis meses e apresentou o sinal negativo para todos. Desta forma, tais resultados ensejam que para o fluxo de exportações para o Mercosul o aumento do risco cambial, na forma de maior volatilidade, impacta negativamente as exportações.

Ao realizar a análise desagregada, organizadas em capítulos da NCM, observou-se que para os Estados Unidos a análise dos produtos manufaturados que representam 66\% (Tabela 11) do total das exportações de manufaturados para este país, e que dos 14 capítulos selecionados, em oito se obteve resultado de cointegração. Porém, somente quatro, capítulos $20,48,68$ e 87, é que apresentaram coeficiente de longo prazo estatisticamente significativo sendo que destes, três apresentaram sinal positivo e um negativo, capítulo 48. Estes resultados contrastam com os da abordagem agregada, visto que o sinal encontrado para os produtos manufaturados foi negativo.

Para a União Europeia, a análise das exportações de produtos básicos organizadas em oito capítulos representou $81 \%$ do total exportado de produtos básicos pelo Brasil para este bloco. Destes oito capítulos de produtos básicos, apenas quatro apresentaram evidências de cointegração e destes, três apresentaram o coeficiente negativo e estatisticamente significativo para a volatilidade na equação de longo prazo.

Já para os produtos manufaturados desagregados exportados para o Mercosul, tem-se que todos apresentaram evidência de cointegração para as variáveis do modelo, equação (6). Isto reforça a ideia que para este bloco a volatilidade da taxa de câmbio influencia as exportações. Então, ao analisar as variáveis no longo prazo, tem-se que a grande maioria dos produtos apresentaram sinais negativos. Estes resultados confirmam os encontrados para a análise agregada, isto é, que a volatilidade aumentaria o risco de fazer comércio e consequentemente se reduziria o comércio internacional.

Sendo assim, tem-se que para as exportações com destino ao Mercosul os resultados evidenciaram que a volatilidade tem um impacto negativo neste fluxo de comércio. Entretanto, para os demais parceiros, Estados Unidos e União Europeia, a relação entre volatilidade e exportações não é tão clara para o período de tempo analisado. Neste sentido, para que se possa aumentar o volume de produtos exportados do Brasil para o Mercosul, há a necessidade de um maior controle sobre a volatilidade da taxa de câmbio por parte do governo brasileiro, principalmente para os produtos que possuem uma maior participação no volume exportado, como os produtos químicos orgânicos; os minérios, escórias e cinzas; os combustíveis minerais, óleos minerais e produtos da sua destilação; os plásticos e suas obras; as obras de pedra, gesso, cimento, amianto, mica ou de matérias semelhantes; as obras de ferro fundido, ferro ou aço; os reatores nucleares, caldeiras, máquinas, aparelhos e instrumentos mecânicos e suas partes; e os veículos automóveis, tratores, ciclos e outros veículos terrestres, suas partes e acessórios. 
Por fim, em termos de limitações do trabalho pode-se citar a mensuração de volatilidade empregada e o nível de agregação empregado nesta análise. Assim, as perspectivas para trabalhos futuros seriam primeiramente trabalhar com informações de exportações e importações mais desagregadas, como a 4 dígitos do SH, e incorporação de outras mensurações de volatilidade, de forma que se tenha um panorama de sensibilidade para várias abordagens de cálculo da volatilidade.

\section{Referências}

AGUIRRE, A.; FERREIRA, A.; NOTINI, H. The impact of exchange rate volatility on Brazilian manufactured exports. Económica La Plata, v. 53, n. 1-2, p. 3-19, 2007.

ARIZE, A.; OSANG, T.; SLOTTJE, D. J. Exchange-rate volatility in Latin America and its impact on foreign trade. International Review of Economics and Finance, v. 17, n. 1, p. 33-44, 2008.

ARORA, S.; BAHMANI-OSKOOEE, M.; GOSWMI, G. G. Bilateral J-curve between India and her trading partners. Applied Economics, v. 35, n. 9, p. 1037-1041, June 2003.

BAHMANI-OSKOOEE, M. Does black-market exchange rate volatility deter the trade flows? Applied Economics, v. 34, n. 18, p. 2249-2255, 2002.

BAHMANI-OSKOOEE, M.; ECONOMIDOU, C.; GOSWAMI, G. Bilateral J-curve between the UK vis-à-vis her major trading partners. Applied Economics. v. 38, n. 8, p. 879-888, 2006.

BAHMANI-OSKOOEE, M.; GOSWAMI, G. A disaggregated approach to test the J-Curve phenomenon: Japan versus her major trading partners. Journal of Economics and Finance, v. 27. n. 1, p. 102-113, 2003.

BAHMANI-OSKOOEE, M.; HARVEY, H.; HEGERTY, S. W. The effects of exchange-rate volatility on commodity trade between the U.S. and Brazil. North American Journal of Economics and Finance, vol. 25, p. 70-93, 2013.

BAHMANI-OSKOOEE, M.; HEGERTY, S. W. Exchange rate volatility and trade flows: A review article. Journal of Economic Studies, v. 34, p. 211-255, 2007.

BAHMANI-OSKOOEE, M.; HEGERTY, S. W. The effects of exchange-rate volatility on commodity trade between the U.S. and Mexico. Southern Economic Journal, v. 79, n. 4, p. 1019-1044, 2009.

BAHMANI-OSKOOEE, M.; MITRA, R. Exchange rate risk and commodity trade between the U.S. and India. Open Economies Review, v. 19, n. 1, p. 71-80, 2008.

BANERJEE, A.; DOLADO, J. J.; MESTRE, R. Error-correction mechanism tests for cointegration in a single-equation framework. Journal of Time Series Analysis, v. 19, n. 3, p. 267-283, 1998.

BANK FOR INTERNATIONAL SETTLEMENTS. Effective exchange rate indices. 2014. Disponível em: < http://www.bis.org/statistics/eer/index.htm>. Acesso em: 02/11/2014 
BITTENCOURT, M.V.L.; LARSON, D.W.; THOMPSON, S.R. Impactos da volatilidade da taxa de câmbio no comércio setorial do Mercosul. Estudos Econômicos, v. 37, n. 4, p. 791-816, 2007.

BRASIL. Ministério de Desenvolvimento, Indústria e Comércio Exterior. Comércio Exterior. 2015. Disponível em: <http:/www.mdic.gov.br/comercio-exterior>. Acesso em: 02 fev. 2015.

CARMO, A. S. S.; BITTENCOURT, M. V. L. O efeito da volatilidade da taxa real de câmbio sobre a diversificação da pauta de exportação do Brasil: uma investigação empírica. In: ENCONTRO NACIONAL DE ECONOMIA, 41., 2013, Foz do Iguaçú. Anais... Foz do Iguaçú: ANPEC, 2013.

CLARK, P.B. Uncertainty, exchange risk, and the level of international trade. Western Economic Journal, v. 11, n. 3, p. 302-313, Sept. 1973.

ELLIOTT, G.; ROTHENBERG, T. J.; STOCK, J. H. Efficient test for an autoregressive unit root. Econometrica, v. 64, n. 4, p. 831-836, 1996.

FRANKE, G. Exchange rate volatility and international trading strategy. Journal of International Money and Finance, v. 10, n. 2, p. 292-307, 1991.

HOOPER, P.; KOHLHAGEN, S.W. The effect of exchange uncertainty on the prices and volume of international trade. Journal of the Japanese and International Economy, v. 8, n.4, p. 483-511, 1978.

LEE, J.; STRAZICICH, M. C. Minimum LM unit root test with one structural breaks. Economics Bulletin, v. 33, n. 4, p. 2483-2492, 2013.

. Minimum LM unit root test with two structural breaks. Review of Economics and Statistics. v. 85, p. 1082-1089, 2003.

LEONARD, G.; STOCKMAN, A. C. Current account and exchange rates: a new look at the evidence. Cambridge, MA: National Bureau of Economic Research, July 2001. (NBER Working Paper Series, n. 8361).

LIN, C. Exchange rate uncertainty and trade. The B.E. Journal of Macroeconomics, v. 12, n. 1, p. 1-35, 2012.

NG, S.; PERRON, P. Lag length selection and the construction of unit root tests with good size and power. Econometrica, v. 69, n. 6, p. 1519-1554, 2001.

PESARAN, M. H.; SHIN, Y.; SMITH, R. J. Bounds testing approaches to the analysis of level relationships. Journal of Applied Economics, v. 16, n. 3, p. 289-326, 2001.

VERHEYEN, F. Bilateral exports from euro zone countries to the US: does exchange rate variability play a role? International Review of Economics $\mathcal{E}$ Finance, v. 24, p. 97-108, Oct. 2012.

VIAENE, J. M.; DE VRIES, C. G. International trade and exchange rate volatility. European Economic Review, v. 36, n. 6, p. 1311-1321, 1992. 
WILLETT, T. D. The Economics and politics of industrial policy: some lessons from the U.S. and Abroad. Contemporary Economic Policy, v. 4, n. 1, p. 10-11, Feb. 1986.

Recebido em: 06/10/2015. Aceito em: 29/08/2016. 